\title{
Structures and Proton-Pumping Strategies of Mitochondrial Respiratory EnZymes
}

\author{
Brian E. Schultz ${ }^{1}$ and Sunney I. Chan ${ }^{1,2}$ \\ ${ }^{1}$ Arthur Amos Noyes Laboratory of Chemical Physics, California Institute of Technology, \\ Pasadena, CA 91125, and \\ ${ }^{2}$ Institute of Chemistry, Academia Sinica, Taipei 11529, Taiwan; \\ email: chans@its.caltech.edu
}

Key Words crystal structures, free energy transduction, mitochondrion, redox linkage, respiratory electron transport chain

- Abstract Enzymes of the mitochondrial respiratory chain serve as proton pumps, using the energy made available from electron transfer reactions to transport protons across the inner mitochondrial membrane and create an electrochemical gradient used for the production of ATP. The ATP synthase enzyme is reversible and can also serve as a proton pump by coupling ATP hydrolysis to proton translocation. Each of the respiratory enzymes uses a different strategy for performing proton pumping. In this work, the strategies are described and the structural bases for the action of these proteins are discussed in light of recent crystal structures of several respiratory enzymes. The mechanisms and efficiency of proton translocation are also analyzed in terms of the thermodynamics of the substrate transformations catalyzed by these enzymes.

\section{CONTENTS}

PERSPECTIVES AND OVERVIEW $\ldots \ldots \ldots \ldots \ldots \ldots \ldots \ldots \ldots \ldots \ldots$

ATP SYNTHASE: A Reversible Rotary Stepping Motor . . . . . . . . . . . . . 26

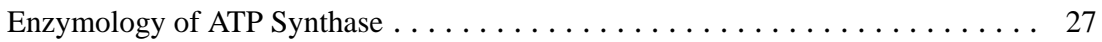

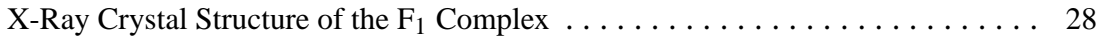

X-Ray Crystal Structure of the $\mathrm{F}_{0}$ Complex . . . . . . . . . . . . . . . . . 29

Observation of Subunit Rotation in ATP Synthase . . . . . . . . . . . . . . 30

Coupling of Proton Transfer and ATP Synthesis . . . . . . . . . . . 30

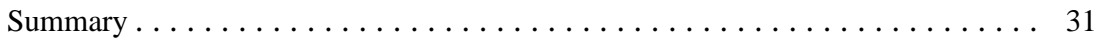

CYTOCHROME $b c_{1}$ : A Redox-Linked Proton Pump Using a Small

Molecule as a Proton Carrier . . . . . . . . . . . . . . . . . . . 32

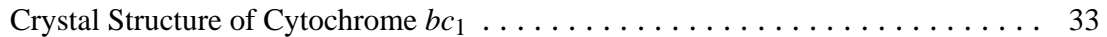

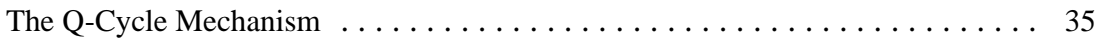

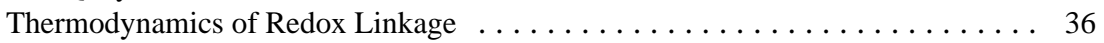

Mechanism of Branched Electron Transfer . . . . . . . . . . . . . 36

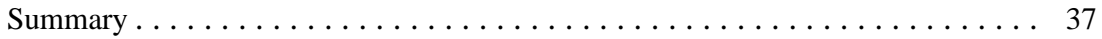


CYTOCHROME $c$ OXIDASE: A Redox-Linked Proton Pump Using

Transmembrane Ion Channels . . . . . . . . . . . . . . . . . . . 38

X-Ray Crystal Structures $\ldots \ldots \ldots$. . . . . . . . . . . . . . . . . . . . . . 39

Proton Channels Inferred from Crystal Structures . . . . . . . . . . . . 40

Mutagenesis Studies and Proton Translocation . . . . . . . . . . . . 41

Comparison of the Crystal Structures of Reduced and Oxidized

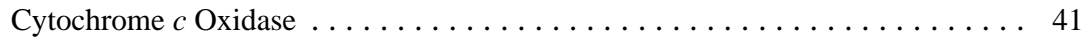

Redox-Linked Changes in Metal Environment and Protein Structure . . . . . . . 42

Reaction of the Enzyme with Dioxygen . . . . . . . . . . . . . . 42

Redox-Coupled Proton Uptake by Cytochrome Oxidase . . . . . . . . . . . . 44

Thermodynamics of Electron Transfer . . . . . . . . . . . . . . 45

Prospects for Further Understanding of the Enzyme . . . . . . . . . . . . 47

NADH:UBIQUINONE OXIDOREDUCTASE: A Proton Pump with an

Unknown Mechanism. . . . . . . . . . . . . . . . . . . . . . . . . 47

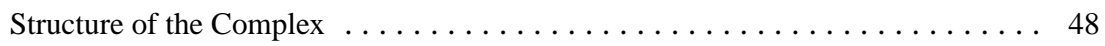

Subunit Description and Localization of Prosthetic Groups . . . . . . . . . . . . 49

The Iron-Sulfur Clusters . . . . . . . . . . . . . . . . . . . . . . . . . 49

The Ubiquinone Binding Sites . . . . . . . . . . . . . . . . . 50

Thermodynamics of Proton Translocation $\ldots \ldots \ldots \ldots \ldots \ldots \ldots \ldots \ldots \ldots$

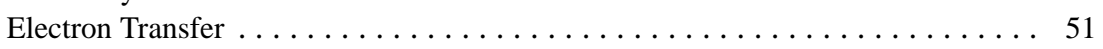

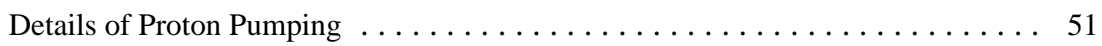

SUCCINATE:UBIQUINONE OXIDOREDUCTASE: A Respiratory

Enzyme That Does Not Pump Protons . . . . . . . . . . . . . . . . . . 52

QFR Crystal Structures ........................... 53

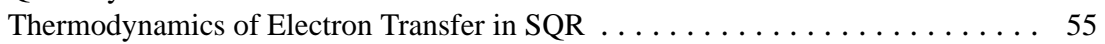

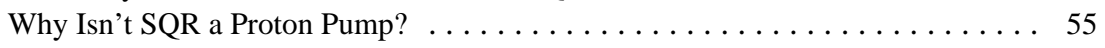

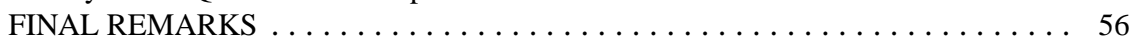

\section{PERSPECTIVES AND OVERVIEW}

The inner mitochondrial membrane of eukaryotes plays host to a fascinating set of molecular machines, the enzymes of the respiratory electron transport chain. This set of enzymes, diagrammed in Figure 1, consists of NADH:ubiquinone oxidoreductase (Complex I), succinate:ubiquinone oxidoreductase (Complex II, SQR), ubiquinone:cytochrome $c$ oxidoreductase (Complex III, cytochrome reductase, cytochrome $b c_{1}$ ), cytochrome $c$ oxidase (Complex IV, cytochrome oxidase), and ATP synthase (Complex V, $\mathrm{F}_{1} \mathrm{~F}_{0}$-ATPase). Complexes I, III, and IV serve as proton pumps, using the energy of electron transfers to perform the electrical work of translocating protons from the matrix to the cytosol of the mitochondrion to produce and sustain an electrochemical gradient across the inner membrane. Under normal physiological conditions, Complex V uses the free energy released from the flow of protons back across the membrane in order to perform the chemical work of producing ATP from ADP and inorganic phosphate. A steady state is achieved in which the translocation of protons from the matrix into the intermembrane space is balanced by the utilization of the protons for ATP synthesis. 
However, under conditions of a high [ATP]/[ADP] ratio and low membrane energization, complex V can work backwards and serve as a proton pump as well. Each of the proton-pumping enzymes utilizes a different strategy for promoting proton translocation, a strategy that is defined by and can be understood in terms of the molecular structures of the proteins. Recently, X-ray crystal structures have been reported for part or all of Complexes II-V. In light of these structures, a glimpse of the mechanisms of these proteins can be obtained.

Complexes I, III, and IV are redox-linked proton pumps. That is, the electron transfers through the enzyme are coupled to an increase in the potential energy of the protein itself, so that the associated conformational changes in the protein drive the unidirectional (vectorial) flow of protons across the membrane. A set of common physical principles applies to these pumps, though the chemical details are different for each one. Three necessities for efficient proton translocation by these enzymes are ( $a$ ) redox linkage, $(b)$ electron gating, and $(c)$ proton gating.

The first requirement, as mentioned above, is that the redox changes that occur during turnover of the protein induce conformational changes in the protein that serve to drive vectorial proton transfer. Three factors can contribute to this linkage: substrate binding, electrostatic interactions involving the redox centers, and changes of coordination geometry at the metal centers involved in the electron transfer and substrate transformation. It should be noted that binding of a redoxactive substrate to an enzyme is in fact redox-linked, as the binding free energy of the substrate is reflected in a change in the reduction potential of the substrate.

Electron gating refers to the necessity that when an electron is transferred to a given redox center, all of the requisite conformational changes and proton transfers must occur prior to the electron passing to the next center in the protein. Failure of this requirement leads to a decoupling of electron transfer and proton transfer referred to as an electron leak. Similarly, proton gating is the requirement that as a proton is moved against the electrochemical potential gradient, protein structural and conformational barriers exist to prevent the backflow of protons toward the matrix side of the membrane. If this condition is not met, electron transfer and proton transfer are again decoupled; this situation is referred to as a proton slip.

It is important to note that redox linkage is predominantly a thermodynamic issue, whereas electron and proton gating are kinetic in nature. For a given reaction intermediate in the proton-pumping reaction pathway, the protein structure is defined by the oxidation state of all of the redox centers and the protonation state of the protein. Hence, redox linkage can be defined completely through the structural description of all of the intermediates in the reaction cycle. Electron leaks and proton slips remove the protein from the proton-pumping reaction pathway. Since electron leaks and proton slips are thermodynamically favored, the thermodynamically most favored outcome in the reaction of a proton-pumping enzyme with its substrates is electron transfer without the associated translocation of protons. Thus, the gating requirements state that the proton pumping reaction pathway must be the most favorable from a kinetic standpoint. Finally, it follows that there must be sufficient redox linkage at each reaction intermediate to allow 
the protein reorganization necessary to ensure the vectorial nature of the overall proton-translocation process.

This review summarizes the current structural knowledge of the enzymes of the respiratory chain and how these structures and associated spectroscopic and enzymological studies have defined the mechanism of proton translocation in the proteins. Emphasis is placed on the structural and thermodynamic aspects of these enzymes. Other biophysical and enzymological data is mentioned only as necessary with regard to the proton translocation function of the enzymes. More detailed information on these aspects of enzyme function may be found elsewhere. Rather than proceeding through the canonical order of Complex I to Complex V, the enzymes are presented in the order of best-understood to least-understood in terms of the proton translocation mechanism. Complex II is not a proton pump and is considered briefly at the end of this work.

\section{ATP SYNTHASE: A Reversible Rotary Stepping Motor}

ATP synthase $\left(\mathrm{F}_{1} \mathrm{~F}_{0}\right.$-ATPase), Complex $\mathrm{V}$ of the respiratory chain, utilizes the electrochemical gradient across the inner mitochondrial membrane to promote the phosphorylation of ADP in order to produce ATP, according to Equation 1, where $n$ is in the range of $3-4(15,16,39,109)$. In terms of function, this protein assembly is analogous to a turbine or rotary motor. The flow of protons through the enzyme promotes the rotation of a large subunit assembly, and the energy from this rotation is utilized for ATP synthesis. The protein is able to function in the opposite direction under conditions of a high [ATP]/[ADP] ratio and low membrane energization (75).

$$
\mathrm{ADP}+\mathrm{P}_{\mathrm{i}}+\mathrm{H}^{+}+n \mathrm{H}^{+}(\text {cytosol }) \rightarrow \mathrm{ATP}+\mathrm{H}_{2} \mathrm{O}+n \mathrm{H}^{+} \text {(matrix) }
$$

The enzyme consists of a membrane-bound subcomplex $\mathrm{F}_{0}$, a large extramembranous complex $\mathrm{F}_{1}$ that resides in the matrix space, and a stalk connecting the two complexes. Figure 2 shows a partial structure of the enzyme that is described in greater detail below. The $\mathrm{F}_{0}$ complex contains an ion channel that allows the flow of protons from the cytoplasmic to the matrix side of the mitochondrial membrane and couples this flow of protons to subunit rotation within the enzyme complex. The mammalian $\mathrm{F}_{0}$ complex contains nine distinct subunits, termed $\mathrm{a}, \mathrm{b}, \mathrm{c}, \mathrm{d}, \mathrm{e}, \mathrm{f}$, $\mathrm{g}, \mathrm{A} 6 \mathrm{~L}$, and $\mathrm{F}_{6}$. There are 9-12 c subunits in the complex, with one copy each of subunits $b$, $d$, and $F_{6}(20,26,27)$. The stoichiometry of the remaining subunits has not been determined to date. A simpler $\mathrm{F}_{0}$ complex from Escherichia coli possesses an $\mathrm{ab}_{2} \mathrm{c}_{9-12}$ subunit composition (42). This latter composition can be considered the minimum necessary for a functional $\mathrm{F}_{0}$ complex.

ATP synthesis and hydrolysis occurs in the $\mathrm{F}_{1}$ complex. This complex has an $\alpha_{3} \beta_{3} \gamma \delta \varepsilon$ subunit composition with a molecular weight of 371,000 . The active sites for ATP synthesis/hydrolysis reside on the $\beta$ subunits, all three of which are involved in overall catalysis in a cooperative fashion as described below. 
The stalk region of the $\mathrm{F}_{1} \mathrm{~F}_{0}$-ATPase consists of subunits from both the $\mathrm{F}_{0}$ and $\mathrm{F}_{1}$ complexes. In the mitochondrial enzyme, the subunit OSCP (oligomycin sensitivity conferring protein) is associated with this region. The stalk provides the mechanical coupling between the proton translocation in the $\mathrm{F}_{0}$ subunit and ATP synthesis/hydrolysis in the $\mathrm{F}_{1}$ complex. With respect to nomenclature, the mitochondrial subunits OSCP and $\delta$ are equivalent to the $\delta$ and $\varepsilon$ subunits in bacteria, respectively, but there is no equivalent to the mitochondrial $\varepsilon$ subunit in bacteria.

\section{Enzymology of ATP Synthase}

The reaction mechanism for ATP synthesis, or in the reverse direction, hydrolysis, was proposed as a binding change mechanism by Paul Boyer in the late 1970s (15). This mechanism has several major features: $(a)$ the function of the $\mathrm{F}_{1}$-ATPase as an integrated trimer; $(b)$ asymmetry of the catalytic $\beta$ subunits, each having different substrate binding and catalysis characteristics; $(c)$ cooperativity between the $\beta$ subunits such that the conformation at one subunit dictates the conformations at the other subunits and vice versa; and $(d)$ an interconversion of the binding characteristics of each subunit as catalysis proceeds. The interconversion between forms was postulated to occur through rotational catalysis, in which the flow of protons through the $\mathrm{F}_{0}$ subcomplex causes a subunit rotation in the $\mathrm{F}_{1}$ complex that changes the properties of the $\beta$ subunits. The mechanism is shown schematically in Figure 3 .

The three conformations of the $\beta$ subunits are referred to as the tight, open, and loose forms. In the reaction cycle, ADP and $\mathrm{P}_{\mathrm{i}}$ bind to the subunit in the loose

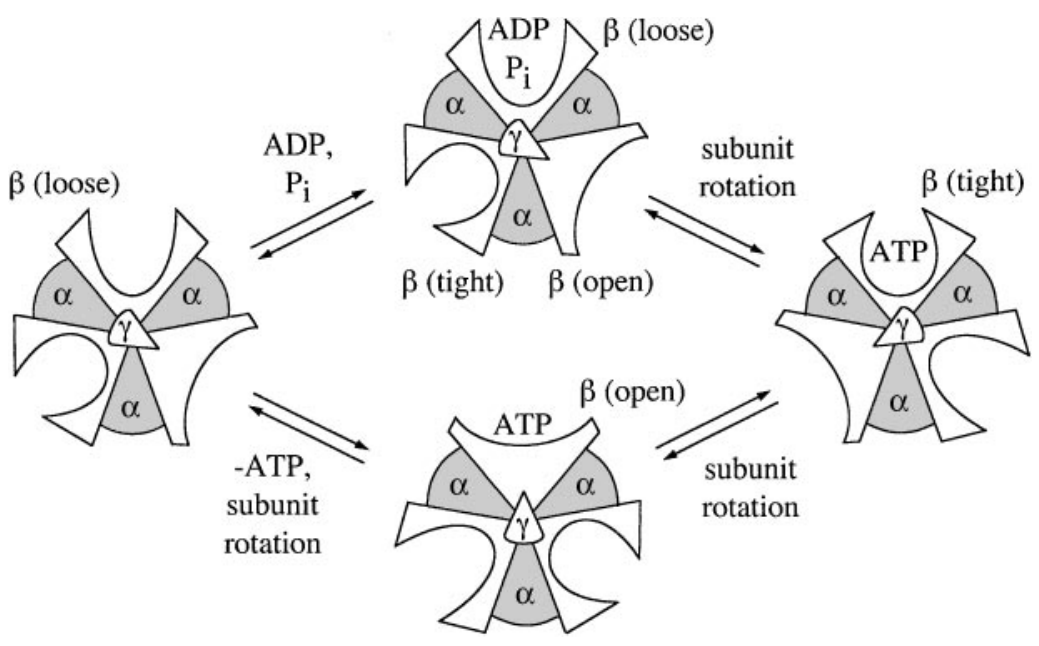

Figure 3 The binding change mechanism of $F_{1}$-ATPase. Only the substrate transformations in the top $\beta$ subunit are shown. Note that in this mechanism only the central $\gamma$ subunit rotates; the $\beta$ subunits change their binding characteristics as a result of the $\gamma$ subunit rotation. 
form. Once this binding occurs, this site is converted to the tight configuration. In the tight configuration, the $\beta$ subunit catalyzes the reaction of ADP and phosphate to form tightly bound ATP. This step does not require energy transduction from the proton gradient, as ATP formation from ADP and phosphate can be observed in isolated $F_{1}$-ATPase. In the next step in the reaction cycle, the reaction site is converted to its open form and ATP is released. This is the step that is coupled to proton translocation, as energy is needed to eliminate the strong binding interaction between ATP and the protein. In a subsequent step, the open form is converted to the loose form to complete the reaction cycle. At any given point in the reaction cycle, one subunit has ATP bound in the tight form, one subunit is in the open form, and the third subunit is in the loose form that will bind ADP and $\mathrm{P}_{\mathrm{i}}$. Only when ATP is released from the open subunit and ADP and $\mathrm{P}_{\mathrm{i}}$ are bound in the loose subunit can the subunit interconversion occur to drive the release of one molecule of ATP and the formation of a second molecule. This strict requirement for the forward reaction of ATP synthase is what gives the holoenzyme tight energy coupling.

Prior to the solution of X-ray crystal structures, the mechanistic insight with regard to this enzyme came from classical enzymology, isotope exchange studies, inhibition and derivatization of the enzyme, and more recently, site-directed mutagenesis. Excellent summaries of these studies have been presented elsewhere $(15,16)$. The following sections provide salient results of recent crystallographic and biophysical studies that reveal the details of the binding change mechanism and validate this hypothesis.

\section{X-Ray Crystal Structure of the $\mathrm{F}_{1}$ Complex}

The crystal structure of the $\mathrm{F}_{1}$-ATPase from bovine heart, with the $\alpha_{3} \beta_{3} \gamma$ subassembly resolved, provided a structural basis for mechanistic proposals of ATP synthesis. Several structures of the $F_{1}$-ATPase have been published $(1,2,11,96,110,123)$, most of which are variants of the original $2.8 \AA$ structure solved by Walker and coworkers (2). This structure, the crystals for which were grown in the presence of ADP and the ATP analog 5'-adenylyl-imidodiphosphate (AMP-PNP), is the most illustrative with respect to the reaction mechanism of the enzyme and serves as the source of the information that follows.

The overall shape of the protein complex is ellipsoidal, with a height of $80 \AA$ and a diameter of $100 \AA$. The complex consists of a pseudo-threefold symmetric ring of alternating $\alpha$ and $\beta$ subunits, with the $\gamma$ subunit sitting asymmetrically in the center of this ring. The $\alpha$ and $\beta$ subunits have a very high sequence similarity (20\% identity) and have nearly identical folds. Each of subunits $\alpha$ and $\beta$ consists of $\beta$-barrel, nucleotide-binding, and helix bundle domains. One of the $\beta$ subunits contains a molecule of AMP-PNP at the catalytic site. A second $\beta$ subunit contains bound ADP at its catalytic site. The third subunit has an empty catalytic site. These subunits appear to correspond to the tight, loose, and open conformations, respectively, of the $\beta$ subunits. 
The nucleotide binding site of the $\beta$ subunits consists of a hydrophobic region in which the adenine moiety binds, and a binding region for the phosphate tail of the nucleotides. The hydrophobic pocket includes residues V164, Y345, F418, A421, and F424. In the AMP-PNP-bound form, shown in Figure 4, residues G159 (amide NH), K162, R189, R373 from an adjacent $\alpha$ subunit, and an $\mathrm{Mg}^{2+}$ ion form electrostatic interactions/hydrogen bonds with the phosphate groups. In the ADP-bound form, residues 159-164, along with R373 from the $\alpha$ subunit and an $\mathrm{Mg}^{2+}$ ion, serve to bind the diphosphate, while an ordered water molecule occupies the position that the terminal phosphate takes in the AMP-PNP-bound form. The overall structures of the ADP-bound and AMP-PNP-bound subunits are very similar.

The empty $\beta$ subunit shows a marked structural change with respect to the AMPPNP-bound form. A disruption of the $\beta$-sheet structure of the nucleotide-binding domain opens up the catalytic site. The distances between F424 and residues K162, R189, and R373 ( $\alpha$ subunit) increase by $2.7 \AA, 8.6 \AA$, and $12.3 \AA$, respectively, in going from the AMP-PNP form to the empty form. This opening allows the release of bound ATP from the $\beta$ subunit.

The asymmetry of the $\beta$ subunits is at least in part induced by the $\gamma$ subunit. In addition, coupling of proton transfer and ATP synthesis requires tight interaction between the $\gamma$ subunit and the $\alpha_{3} \beta_{3}$ ring. Both hydrogen-bonding and hydrophobic interactions were observed between the $\gamma$ subunit and specific subunits on the ring. Specific hydrogen-bonding interactions include those of R254 and Q255 of the $\gamma$ subunit interacting with D316, T318, and D319 on the empty $\beta$ subunit, R252 of the $\gamma$ subunit hydrogen bonding to $\mathrm{D} 333$ of an $\alpha$ subunit adjacent to the empty $\beta$ subunit, and K87 of the $\gamma$ subunit interacting with E398 of the AMP-PNP-bound $\beta$ subunit. These, in combination with several hydrophobic interactions occurring between the $\gamma$ subunit and the $\alpha_{3} \beta_{3}$ subcomplex, provide the coupling between these subunits.

\section{X-Ray Crystal Structure of the $\mathrm{F}_{0}$ Complex}

A recent crystal structure of an $\mathrm{F}_{1} \mathrm{c}_{10}$ complex from Saccharomyces cerevisiae at $3.9 \AA$ resolution has yielded a partial structural description of the $\mathrm{F}_{0}$ complex of ATP synthase, as well as structural information regarding the linkage between the $\mathrm{F}_{0}$ and $\mathrm{F}_{1}$ complexes (116). The structure is shown in Figure 2. In this structure, the $\alpha, \beta, \gamma$, and $\delta$ subunits of $\mathrm{F}_{1}$ were present, along with $10 \mathrm{c}$ subunits of $\mathrm{F}_{0}$. The $\mathrm{c}$ subunits are arranged in a ring. Each c subunit consists of two membranespanning $\alpha$-helices connected by a loop region that extends into the matrix space. The subunits are oriented so that they form a cylindrical shell, with the N-terminal helices on the inside of the shell and the C-terminal helices on the outside. Although the resolution of the structure is low, it appears that the $\delta$ subunit of $\mathrm{F}_{1}$ makes contact with five c subunits, interacting with the loop regions of these subunits. The $\gamma$ subunit shows interactions with three c subunits. The $\varepsilon$ subunit, while not yet structurally or spatially defined, is believed to be present in the stalk region as well. 
Each of the c subunits of all known $\mathrm{F}_{0}$-ATPases contains a carboxylate group (Asp or Glu) that can react with DCCD to inactivate the enzyme $(39,108)$. This residue, D61 in E. coli, was shown through NMR structures to reside near the middle of the C-terminal helix of the subunit (47), which places the residue in the middle of the mitochondrial membrane. The equivalent residue E59 in the Saccharomyces cerevisiae enzyme was not resolved in the $\mathrm{F}_{1} \mathrm{c}_{10}$ structure but is predicted to lie in a similar position. Mutagenesis studies have shown that residues $\mathrm{R} 210, \mathrm{E} 219$, and $\mathrm{H} 245$ in the E. coli a subunit are also crucial for proton translocation (60). Thus, it is assumed that the proton channel lies in the interface between the a and c subunits, and that interactions between the a and c subunits involving the aforementioned amino acids are crucial for proton translocation.

\section{Observation of Subunit Rotation in ATP Synthase}

Direct observation of rotation of the $\gamma$ subunit of ATP synthase with respect to the $\alpha_{3} \beta_{3}$ subunit cluster was accomplished in a truly elegant experiment by Noji et al (87). An $\mathrm{F}_{1}$-ATPase from the thermophilic bacterium Bacillus PS3 was expressed in $E$. coli and modified with polyhistidine tags on the $\beta$ subunits and with a cysteine residue introduced on the $\gamma$ subunit. The His-tags were used to immobilize the $\alpha_{3} \beta_{3}$ substructure on a coverslip coated with nickel nitrilotriacetate. The cysteine on the $\gamma$ subunit was biotinylated and attached to an actin filament that was modified with both a fluorophor and a biotin molecule, using streptavidin as a linker. When ATP was introduced to these molecules, hydrolysis of the ATP by the $\mathrm{F}_{1}$ complex caused the $\gamma$ subunit and the attached actin filament to rotate. The actin filament was sufficiently long $(\sim 2.5 \mu \mathrm{m})$ that the rotation of this filament was observable by epifluorescence microscopy. Rotation was only observed in a counterclockwise direction. A similar experiment demonstrated that the $\varepsilon$ subunit is also part of the rotor (66).

Using the same methodology as described above, Sambongi et al demonstrated rotation of the oligomer of c subunits during ATP hydrolysis by the E. coli $\mathrm{F}_{1} \mathrm{~F}_{0^{-}}$ ATPase (107). A glutamate in the c subunit of the $F_{0}$ complex was replaced by a cysteine, and this cysteine was used as above to bind a fluorescently labeled actin filament. Again, a counterclockwise rotation of the actin filament was observed upon addition of ATP.

These two experiments demonstrated the operation of the $\mathrm{F}_{1} \mathrm{~F}_{0}$-ATPase as a rotary motor, showed the linkage between the $\mathrm{F}_{0}$ and $\mathrm{F}_{1}$ complexes, and revealed at least in part the role that the subunits play in the functioning of this machine. The bacterial $\mathrm{c}, \gamma$, and $\varepsilon$ subunits are involved in the rotor portion of the molecule, whereas the $\mathrm{a}, \mathrm{b}, \alpha$, and $\beta$ subunits remain stationary during enzyme turnover. It should be noted that in the absence of a tether between the $(\alpha \beta)_{3}$ trimer and the $\mathrm{F}_{0}$ subunit, rotation of the $\gamma$ subunit would rotate the entire $F_{1}$ subunit. The b subunit appears to provide this tether in the functioning holoenzyme.

\section{Coupling of Proton Transfer and ATP Synthesis}

The energy cost $\Delta \mathrm{G}^{\circ}$ for the formation of ATP and water from ADP, phosphate, and one proton is $8.2 \mathrm{kcal} / \mathrm{mol}$. The protonmotive force $(\Delta \psi-2.3 R T \Delta \mathrm{pH} / F)$ across 
an energized membrane is approximately $200 \mathrm{mV}$. On this basis, the flow of two protons through the $\mathrm{F}_{1} \mathrm{~F}_{0}$-ATPase complex $(\Delta \mathrm{G} \sim 9.2 \mathrm{kcal} / \mathrm{mol})$ would be sufficient to produce one molecule of ATP under standard conditions. Experimental measurements suggest a stoichiometry of 3-4 protons per ATP molecule formed $(30,117,124)$. Assuming that the ten-subunit structure of the $c$ assembly of $F_{0}$ is correct, and that the rotation of this assembly $36^{\circ}\left(360^{\circ} / 10\right)$ requires one proton, 3.3 protons would be required for the synthesis of one molecule of ATP. Thus, the efficiency of ATP synthesis with respect to free energy consumption is much less than unity. The transmembrane potential must provide an important driving force and kinetic determinant in the coupling of the proton gradient to the subunit rotation of the $\mathrm{F}_{1} \mathrm{~F}_{0}$ stepping motor if the coupling of ATP hydrolysis to the subunit rotation is very tight.

The strength of the coupling of ATP hydrolysis to $\gamma$ and $\mathrm{c}$ subunit rotation has been assessed through the direct observation of the subunit rotation described above $(87,107)$. For actin filaments with lengths in the range of $1-4 \mu \mathrm{m}$, a consistent torque of approximately $40 \mathrm{pN} \mathrm{nm}$ was produced in the presence of a high concentration (2-5 mM) of ATP. This torque corresponds to a free energy requirement of $36 \mathrm{kcal} / \mathrm{mol}$ for a full rotation of the ATPase motor. The hydrolysis of 3 molecules of ATP under standard conditions is associated with a $\Delta \mathrm{G}$ of $-24.6 \mathrm{kcal} / \mathrm{mol}$; therefore, the extra driving force necessary to rotate the actin filaments arose from the high $[\mathrm{ATP}] /[\mathrm{ADP}]$ ratio used in the experiments. Because the rotation of the actin filament can be driven with only a small excess of driving force, the coupling of the ATP hydrolysis and subunit rotation must be both thermodynamically and kinetically very tight.

At a fundamental level, the energy transduction in ATP synthase is relatively straightforward. In the forward direction, electrostatic interactions between the protons and amino acids in the subunits of the $\mathrm{F}_{0}$ complex drive the rotor. Uncoupling of the proton transfer and ATP synthesis is prevented by the apparent requirement that the $\gamma$ subunit, and hence the entire rotor, cannot move until the proper nucleotides bind to the $\mathrm{F}_{1}$ complex. In the opposite direction, ATP hydrolysis can allow the rotor to rotate, but the rotation will either break favorable electrostatic interactions within the $\mathrm{F}_{0}$ subcomplex or create unfavorable ones. Without the uptake and transport of protons to counteract these unfavorable electrostatic interactions, ATP hydrolysis will not provide enough energy to move the rotor. Thus, through simple, mechanical coupling, the reversible energy transduction between an electrochemical gradient and a phosphate bond in ATP can be achieved.

\section{Summary}

The structural, enzymological, and biophysical information gathered to date has led to a detailed understanding of the action of the $\mathrm{F}_{1} \mathrm{~F}_{0}$-ATPase. The structural basis for ATP synthesis/hydrolysis has been characterized, the operation of the enzyme as a rotary stepping motor has been confirmed, the subunits involved in the rotor have for the most part been elucidated, and the coupling of proton transfer to ATP synthesis is clear at least at a conceptual level. Several questions still remain, 
however. The location of the remaining subunits in the overall structure of the holoenzyme needs to be defined at a molecular level, and the roles of the subunits that are found in mitochondrial $\mathrm{F}_{1} \mathrm{~F}_{0}$-ATPase but not in $E$. coli need to be understood. The precise pathway of proton transfer through the $\mathrm{F}_{0}$ subunit is still unknown, and the interactions between the a and the c subunits that lead to rotation of the rotor are still poorly understood. Also, when the enzyme is performing ATP hydrolysis, the mechanism by which this hydrolysis is tightly coupled to proton transfer against the electrochemical gradient across the membrane needs to be discerned.

\section{CYTOCHROME $b c_{1}$ : A Redox-Linked Proton Pump Using a Small Molecule as a Proton Carrier}

Cytochrome $b c_{1}$ catalyzes the transfer of electrons from ubiquinol to ferricytochrome $c$, according to Equation $2(18,118,119)$. The reaction is complicated in that both oxidation of ubiquinol $\left(\mathrm{QH}_{2}\right)$ and reduction of ubiquinone $(\mathrm{Q})$ occur during the reaction cycle as part of the proton-translocating apparatus.

Proton translocation mediated by this enzyme occurs in two ways. First, the oxidation of ubiquinol and the accompanying release of protons occur on the cytoplasmic side of the mitochondrial membrane, whereas the reduction of ubiquinone by Complexes I and II (see below) involves uptake of protons from the matrix space. In this way, ubiquinone acts as a shuttle for protons, transporting them in an uncharged form across the mitochondrial membrane. The second method of proton translocation involves a Q-cycle, a branched electron transfer pathway in which one electron from the oxidation of ubiquinol is used to reduce ferricytochrome $c$ on the cytoplasmic side of the membrane, while the other electron is used to reduce ubiquinone (or ubisemiquinone) to ubisemiquinone (or ubiquinol) with the associated uptake of protons from the matrix space. Two ubiquinol molecules are oxidized in each reaction cycle, reducing two molecules of ferricytochrome $\mathrm{c}$ and one molecule of ubiquinone. The Q-cycle is the mechanism by which cytochrome $b c_{1}$ serves as a proton pump.

$2 \mathrm{QH}_{2}+2$ cyt $c^{3+}+\mathrm{Q}+2 \mathrm{H}^{+}($matrix $) \rightarrow 2 \mathrm{Q}+2$ cyt $c^{2+}+\mathrm{QH}_{2}+4 \mathrm{H}^{+}($cytosol $)$

Mitochondrial cytochrome $b c_{1}$ exists functionally as a dimer, where each monomer consists of eleven subunits and has a molecular weight of 240,000. Three subunits, cytochrome $b$, cytochrome $c_{1}$, and an iron-sulfur protein, contain all of the redox-active metal centers of the enzyme and constitute the catalytic core of the protein. Cytochrome $b$ contains two six-coordinate low-spin $b$ hemes, $b_{\mathrm{L}}$ and $b_{\mathrm{H}}$ (also called $b_{565}$ and $b_{560}$ ), and two ubiquinol/ubiquinone binding sites, the $\mathrm{P}$ center and the $\mathrm{N}$ center (also known as the $\mathrm{Q}_{0}$ and $\mathrm{Q}_{\mathrm{i}}$ sites). The iron-sulfur protein contains a high-potential $\mathrm{Fe}_{2} \mathrm{~S}_{2}$ cluster, and cytochrome $c_{1}$ contains a six-coordinate low-spin $c$ heme. Cytochrome $c_{1}$ serves as the electron donor to cytochrome $c$. 


\section{Crystal Structure of Cytochrome $b c_{1}$}

Several X-ray crystal structures of mitochondrial cytochrome $b c_{1}$ have been reported $(28,29,63,67,142,147)$. Through the analysis of enzymes from different species and with the use of enzyme inhibitors, a set of conformational states of the enzyme has been defined. With the exception of the iron-sulfur protein and the inhibitor binding sites, the structural information concerning the enzyme has been consistent between studies, and thus the consensus structure will not be described except when necessary.

The structure of the enzyme is dimeric and is best described as pear-shaped (see Figure 1). The height of the protein is approximately $150 \AA$, and its diameter at its widest point in the matrix space is about $130 \AA$. The enzyme extends $30-40 \AA$ into the cytoplasmic space, spans the $40 \AA$ inner mitochondrial membrane, and projects 75-80 $\AA$ into the matrix space. Besides cytochrome $b$, cytochrome $c_{1}$, and the iron-sulfur protein, the monomer is made up of two subunits termed the core 1 and core 2 proteins, and subunits $6-11$. The core 1 and core 2 subunits, along with subunits 6 and 9, lie entirely in the matrix space. Cytochrome $b$, cytochrome $c_{1}$, the iron-sulfur protein, and subunits 7, 10, and 11 span the membrane, whereas subunit 8 lies solely on the cytoplasmic side of the membrane. Figure 5 shows the structure of cytochrome $b$, cytochrome $c_{1}$, and the iron-sulfur protein, the subunits in which the enzyme reaction chemistry occurs.

Cytochrome $b$ consists of eight transmembrane helices $(\mathrm{A}-\mathrm{H})$ connected by loop regions. Helices A-D form a four-helix bundle within which both $b$ hemes are bound. Heme $b_{\mathrm{L}}$ is bound by residues $\mathrm{H} 83$ and $\mathrm{H} 182$ on helices $\mathrm{B}$ and D, respectively. Heme $b_{\mathrm{H}}$ is ligated by $\mathrm{H} 97$ and $\mathrm{H} 196$ from helices B and D. The closest approach of the two hemes is at $8.2 \AA$, allowing for efficient electron transfer between the two hemes. The $\mathrm{N}$ center of the protein has been defined by structures of the enzyme in the presence and absence of the $\mathrm{N}$ center inhibitor antimycin. The binding pocket is formed by residues from helices $\mathrm{A}, \mathrm{D}$, and $\mathrm{E}$, and a short helix near the $\mathrm{N}$ terminus of the peptide chain. Heme $b_{\mathrm{H}}$ is adjacent to this pocket, and the electron density for antimycin suggests that this inhibitor binds within $4 \AA$ of heme $b_{\mathrm{H}}$. By analogy, ubiquinone should bind in a similar if not identical fashion at this site. The $\mathrm{P}$ center of the protein lies within cytochrome $b$ near the interface of this subunit and the iron-sulfur protein. It consists primarily of residues from helix $\mathrm{C}$, helix $\mathrm{F}$, the loop region connecting helices $\mathrm{C}$ and $\mathrm{D}$, and the loop connecting helices $\mathrm{E}$ and $\mathrm{F}$. Residues from the iron-sulfur protein interact with this site as well, as described below.

Cytochrome $c_{1}$ consists of a sizable extramembranous domain on the cytoplasmic side of the membrane along with a single transmembrane helix to anchor the subunit to the membrane. The fold of the extramembranous domain is related to that of other cytochromes $c$, as discussed elsewhere $(7,147)$. Residues C37 and C40 are involved in thioether linkages to the heme, and H41 and M160 serve as the axial ligands of the heme. A methyl group on the porphyrin ring is 
solvent-exposed, likely near the binding site for cytochrome $c$, while one of the propionate groups of the heme extends toward the iron-sulfur protein.

The iron-sulfur protein contains a transmembrane helix (removed from Figure 5 for clarity) and a hydrophilic domain on the cytoplasmic side of the inner mitochondrial membrane. The subunit extends across the interface between the two monomeric units, with the transmembrane helix in one monomer and the extramembranous domain within the other. This bridging of the monomeric units implies that the structural integrity of the complex and thus its activity depends on the existence of the complex in its dimeric form. However, each of the two catalytic units, composed of cytochrome $b$, cytochrome $c_{1}$, and the extramembranous domain of the iron-sulfur protein, is spatially isolated and operates independently of the other unit. In the iron-sulfur protein, the $\mathrm{Fe}_{2} \mathrm{~S}_{2}$ cluster lies near the edge of the extramembranous domain, bound by C139, H141, C158, and H161.

A comparison of reported crystal structures has revealed that the extramembranous domain of the iron-sulfur protein can adopt a range of positions, suggesting that domain movement is an integral part of the reaction mechanism of the enzyme. The motion connecting the observed forms is a rotation of the iron-sulfur cluster domain made possible by a flexible tether consisting of amino acid residues 67-73 in the iron-sulfur protein. The range of this motion is illustrated in Figure 5 by the superposition of the structures of the iron-sulfur protein at the two extremes of subunit movement. One structure was determined in the presence of the inhibitors stigmatellin and antimycin; the other was determined in the absence of inhibitors (147). In the presence of inhibitors, the iron-sulfur cluster is adjacent to the $\mathrm{P}$ center of the enzyme, with a distance between the iron-sulfur cluster and the iron of the $b_{\mathrm{L}}$ heme of $26 \AA$, and a $32 \AA$ gap between the iron-sulfur cluster and the $c$ heme iron. In the absence of inhibitors, the iron-sulfur cluster is adjacent to the $c$ heme, with H161 in hydrogen-bonding contact with a propionate on the $c$ heme. In this configuration, the distance between the iron-sulfur cluster and the iron of the $b_{\mathrm{L}}$ heme is $34 \AA$, and the distance between the iron-sulfur cluster and the $c$ heme iron is $21 \AA$. The implications of this domain movement with respect to reaction mechanism are discussed below.

Binding of inhibitors at the $\mathrm{P}$ center of the enzyme has revealed two overlapping pockets at which substrate can bind. In the crystal structure of the enzyme incubated with stigmatellin, the iron-sulfur cluster is in contact with the P center $(28,67)$. The electron density for stigmatellin suggests a close interaction with H161 of the ironsulfur protein, most likely in the form of a hydrogen bond. A distance of $12 \AA$ was estimated between the stigmatellin and heme $b_{\mathrm{L}}$. Crystals grown in the presence of myxothiazole or methoxyacrylate-stilbene reveal that the ring structures of these two inhibitors are displaced approximately $5.5 \AA$ toward heme $b_{\mathrm{L}}$, relative to the position of stigmatellin (28). Also, the iron-sulfur cluster was oriented toward the $c_{1}$ heme in these crystals and was thus not interacting directly with the inhibitors. 5-Undecyl-6-hydroxy-4,7-dioxobenzothiazol (UHDBT) appears to bind in a position intermediate between those of stigmatellin and myxothiazole, with a weak interaction between the inhibitor and the iron-sulfur protein (67). 


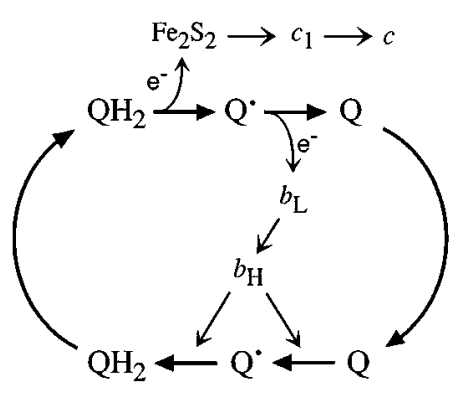

Figure 6 Schematic diagram of the Q-cycle mechanism of cytochrome $b c_{1}$. Thick arrows denote substrate transformation or movement. Thin, barbed arrows denote electron transfer. Q: ubiquinone; $\mathrm{Q}^{\bullet}$ : ubisemiquinone; $\mathrm{QH}_{2}$ : ubiquinol.

$\mathrm{N}$ center

\section{The Q-Cycle Mechanism}

The Q-cycle mechanism for turnover of cytochrome $b c_{1}$ was first proposed by Mitchell (81) to explain the phenomenon of oxidant-induced reduction, in which the reduction level of the $b$ hemes in anaerobic, succinate-reduced mitochondria increased upon exposure of the mitochondria to dioxygen, particularly in the presence of the inhibitor antimycin. The cycle, diagrammed in Figure 6, takes advantage of the fact that ubiquinol is a two-electron reductant but is oxidized in one-electron steps. The reaction cycle begins with ubiquinol binding to the $\mathrm{P}$ center of the enzyme. In the oxidation of ubiquinol, one electron is passed to the high-potential iron-sulfur cluster, which subsequently transfers the electron to cytochrome $c_{1}$, after which the electron is passed to ferricytochrome $c$. The second electron in the oxidation of ubiquinol is transferred to heme $b_{\mathrm{L}}$, then to heme $b_{\mathrm{H}}$, where it is used to reduce a molecule of ubiquinone at the $\mathrm{N}$ site to its semiquinone form $\left(\mathrm{Q}^{\bullet}\right)$. The two protons released during the oxidation of the quinol molecule are released on the cytoplasmic side of the membrane. To complete the reaction cycle, a second molecule of ubiquinol is oxidized at the $\mathrm{P}$ center with the associated release of two protons to the cytoplasmic side of the membrane. Again, one electron is transferred to the iron-sulfur protein, then to cytochrome $c_{1}$, and finally to a second molecule of ferricytochrome $c$. The second electron is transferred through hemes $b_{\mathrm{L}}$ and $b_{\mathrm{H}}$ and used to promote the reduction of the semiquinone at the $\mathrm{N}$ center to ubiquinol, with the associated uptake of two protons from the matrix side of the membrane. The full reaction cycle consists of the oxidation of two molecules of ubiquinol with the associated release of four protons to the cytoplasmic side of the membrane, the reduction of one molecule of ubiquinone coupled to the uptake of two protons from the matrix space, and the reduction of two molecules of ferricytochrome $c$. Overall, four protons are released for every two molecules of ferricytochrome $\mathrm{c}$ reduced, giving a $2 \mathrm{H}^{+} / 1 \mathrm{e}^{-}$proton translocation stoichiometry.

Two points regarding this mechanism are especially noteworthy. First, the branched electron transfer doubles the efficiency of proton translocation mediated by this enzyme. If the reaction catalyzed by this enzyme consisted solely of electron transfer from ubiquinol to cytochrome $c$, the reduction of one molecule of ferricytochrome $c$ would be associated with the release of one proton, not two 
as is observed. By cycling half of the electrons from ubiquinol oxidation back into the membrane-bound quinone pool, the enzyme combines proton pumping with the simple redox-linked release of protons that occurs during ubiquinol oxidation. Second, the branched electron transfer in the enzyme is under kinetic control, not thermodynamic control. The thermodynamically favored reaction is the transfer of both electrons from ubiquinol to ferricytochrome $c$, bypassing the $b$ hemes altogether. Thus, directing the second electron from the oxidation of ubiquinol into cytochrome $b$ instead of the iron-sulfur cluster is at the heart of proton pumping in this enzyme.

\section{Thermodynamics of Redox Linkage}

The overall reaction of cytochrome $b c_{1}$ as shown in Equation 2 is associated with a free energy change of $380 \mathrm{meV}$ under standard conditions. Proton translocation consists of the transfer of 2 protons across the entire mitochondrial membrane and the transfer of 2 protons from membrane-bound ubiquinol to the cytoplasmic space. Two electrons are transferred from ubiquinol to ferricytochrome $c$ in the intermembrane space as well. Assuming a protonmotive force of $200 \mathrm{mV}$ across the mitochondrial membrane, a minimum of $400 \mathrm{meV}$ of energy is necessary to promote proton translocation at the observed stoichiometry. Thus, the enzyme must operate at a high $\left(\left[\mathrm{QH}_{2}\right][\right.$ ferricytochrome $\left.c]\right) /([\mathrm{Q}][$ ferrocytochrome $c])$ ratio under physiological conditions. By comparison, the electron transfer from two molecules of ubiquinol to four molecules of ferricytochrome $c$ has a free energy change of $760 \mathrm{meV}$ under standard conditions. Thus, it is clear that the non-proton-pumping pathway in cytochrome $b c_{1}$ is much more favored thermodynamically than the proton-pumping pathway. In order for proton pumping to occur, the branching of electron transfer in the enzyme must be kinetically favored over transfer of all electrons to ferricytochrome $c$.

The approximate reduction potentials of the heme $b_{\mathrm{L}}$, heme $b_{\mathrm{H}}$, the $\mathrm{Fe}_{2} \mathrm{~S}_{2}$ cluster, and heme $c_{1}$ are $-90,40,280$, and $250 \mathrm{mV}$, respectively $(105,119)$. Ubiquinol has a two-electron reduction potential of $60 \mathrm{mV}$. However, the one-electron $\mathrm{Q} / \mathrm{QH}_{2}$ couple associated with the transfer of the first electron from ubiquinol will be substantially higher than $60 \mathrm{mV}$, and conservation of energy requires that the $\mathrm{Q} / \mathrm{Q}^{\bullet}$ couple be much less than $60 \mathrm{mV}$. This divergence of one-electron potentials for ubiquinone means that $(a)$ a high-potential redox center $\left(\mathrm{Fe}_{2} \mathrm{~S}_{2}\right)$ is necessary to promote the one-electron oxidation of ubiquinol, and $(b)$ heme $b_{\mathrm{L}}$, in spite of its low reduction potential, is still thermodynamically competent to accept an electron from ubisemiquinone at the $\mathrm{P}$ center of the enzyme. In addition, destabilization of ubisemiquinone at the $\mathrm{P}$ center through protein movements could increase the driving force for electron transfer to heme $b_{\mathrm{L}}$. Thus, the branched electron transfer in cytochrome $b c_{1}$ is reasonable from a thermodynamic standpoint.

\section{Mechanism of Branched Electron Transfer}

As described above, branched electron transfer in cytochrome $b c_{1}$ requires that one of the two electrons in the oxidation of ubiquinol is directed through cytochrome 
$b$ rather than the iron-sulfur cluster. The crystal structures of the enzyme have provided clues as to why this branched electron transfer occurs. First, the domain movement of the iron-sulfur protein suggests that electron transfer from semiquinone to heme $b_{\mathrm{L}}$ is likely to be more rapid than the diffusional motion of the iron-sulfur cluster that is necessary for the reduction of heme $c_{1}$. In the time it takes for the iron-sulfur cluster to diffuse toward cytochrome $c_{1}$, be oxidized, and return to the $\mathrm{P}$ center, the electron will have already travelled through the $b$ hemes. This is in accord with single-turnover experiments of quinol with cytochrome $b c_{1}$, in which heme $b$ reduction is more rapid than that of heme $c_{1}(32,54,115)$. Additionally, the different sites of inhibitor binding in the $\mathrm{P}$ center suggest two binding modes for the intermediates in quinol oxidation, of which one may be specific for ubiquinol, whereas the other is appropriate for ubisemiquinone. Under this hypothesis, ubiquinol would bind to the $\mathrm{P}$ center in a position similar to that observed for stigmatellin. After one electron has been transferred to the iron-sulfur cluster, movement of the semiquinone into a binding site similar to that for myxathiazole would occur. This places the semiquinone closer to heme $b_{\mathrm{L}}$, increasing the rate of electron transfer to the heme and decreasing the chance that the semiquinone will bypass the proton-pumping pathway and transfer its electron to the re-oxidized iron-sulfur cluster instead. This aspect of the reaction chemistry was proposed as a "catalytic switch" model, prior to the solution of the enzyme crystal structure, on the basis of biochemical evidence (19). It serves as an example of the protein conformational changes necessary for redox linkage, proton gating, and electron gating. Another factor in the branched electron transfer is the possibility that the reduced iron-sulfur cluster is held at the $\mathrm{P}$ center until the semiquinone migrates to the second binding site, providing a further impediment to electron leakage through the high-potential electron transfer pathway. Resolution of the nature and importance of these various effects constitutes the major remaining issue in understanding the fundamental proton translocation process in this enzyme.

Following the formation of semiquinone at the $\mathrm{P}$ center, the remaining energy transduction by cytochrome $b c_{1}$ arises from electron transfer through cytochrome $b$ to generate semiquinone or quinol at the $\mathrm{N}$ center. The electron transfer from semiquinone to the $b_{\mathrm{H}}$ heme and the $\mathrm{N}$ center increases the potential energy of cytochrome $b$ by introducing a negative charge at the $\mathrm{N}$ center. Relaxation of the protein involves compensation of the negative charge through proton uptake, and reduction of quinone or semiquinone at the $\mathrm{N}$ center completes the electron transfer through the enzyme. This latter step might be linked to movement of the $\mathrm{Fe}_{2} \mathrm{~S}_{2}$ center as well.

\section{Summary}

The crystal structures of cytochrome $b c_{1}$ have provided a structural context for the Q-cycle model of proton translocation in the enzyme and have provided insight into the details of the branched electron transfer that lies at the heart of the proton-translocating mechanism. As expected for a molecular machine, significant changes in the structure of the protein take place during the reaction cycle as a 
result of substrate binding, electrostatic interactions, and intrinsic domain movements. Of the redox-linked proton pumps in the respiratory chain, cytochrome $b c_{1}$ is the most thoroughly understood from a mechanistic standpoint. Although the other redox-linked proton pumps in the respiratory chain operate via different mechanisms, the mechanism of cytochrome $b c_{1}$ can serve as a basis for understanding the requirements for proton pumping on a molecular level, particularly with regard to how conformational changes within an enzyme can promote proton pumping in preference to nonproductive electron transfer through the enzyme that is thermodynamically favored.

\section{CYTOCHROME $c$ OXIDASE: A Redox-Linked Proton Pump Using Transmembrane Ion Channels}

Cytochrome $c$ oxidase catalyzes the transfer of electrons from ferrocytochrome $c$ to dioxygen in the terminal step of respiration, oxidizing cytochrome $c$ to its ferric form and reducing the dioxygen to water (Equation 3; 74, 77, 86). Four protons are taken up from the matrix side of the membrane to form the water (scalar protons). In addition, up to four protons are pumped vectorially from the matrix side to the cytoplasmic side of the membrane (vectorial protons). Both of these processes contribute to the formation of the electrochemical gradient across the membrane. Unlike cytochrome $b c_{1}$, cytochrome oxidase does not utilize a small molecule to transport protons across the mitochondrial membrane. Rather, the enzyme relies on one or more transmembrane ion channels as conduits for protons and uses conformational changes to move the pumped protons across the osmotic barrier. Thus, redox linkage is manifested in conformational changes in these channels that promote the unidirectional flow of protons. The presence of the transmembrane proton channels introduces proton slippage in this enzyme, in addition to the ever-present issue of electron leaks.

4 cyt $c^{2+}+\mathrm{O}_{2}+4 \mathrm{H}^{+}($scalar $)+4 \mathrm{H}^{+}$(matrix) $\rightarrow 4$ cyt $c^{3+}+\mathrm{H}_{2} \mathrm{O}+4 \mathrm{H}^{+}$(cytosol)

Mitochondrial cytochrome $c$ oxidase is a 13-subunit enzyme with a molecular weight of 200,000. Subunits I-III are encoded in the mitochondrial DNA, while the remaining genes are located in the nuclear DNA. The enzyme contains four redox centers: $\mathrm{Cu}_{\mathrm{A}}$, a binuclear copper center located in subunit II; $\mathrm{Cu}_{\mathrm{B}}$, a mononuclear copper found in subunit I; and two hemes, a six-coordinate low-spin heme $a$ and a five-coordinate high-spin heme $a_{3}$, both of which are also located in subunit I. Heme $a_{3}$ and $\mathrm{Cu}_{\mathrm{B}}$ form a binuclear site at which dioxygen binds and is reduced to water. $\mathrm{Cu}_{\mathrm{A}}$ serves as the initial electron acceptor from cytochrome $c$, and heme $a$ mediates electron transfer from $\mathrm{Cu}_{\mathrm{A}}$ to the heme-copper center.

Bacterial cytochrome $c$ oxidases ( $a a_{3}$ oxidases) typically contain three or four subunits, and almost all have homologs to the mammalian subunits I-III. Other enzymes related structurally and functionally to cytochrome oxidase exist in bacteria 
as well. In particular, many bacteria possess quinol oxidase enzymes that are closely related to the cytochrome $c$ oxidases (46). As with the cytochrome $c$ oxidases, these quinol oxidases contain a highly conserved subunit containing a low-spin heme and a heme-copper dioxygen reduction site. The orientation of the redox centers and the dioxygen reduction chemistry of these enzymes are essentially the same as in the cytochrome oxidases. However, the quinol oxidase enzymes do not contain the $\mathrm{Cu}_{\mathrm{A}}$ site. In addition, the use of quinol as an electron donor rather than ferrocytochrome $c$ requires mechanistic differences in proton translocation between quinol oxidases and cytochrome $c$ oxidases. Nevertheless, on account of the many structural and chemical similarities between the two types of enzymes, the absence of $\mathrm{Cu}_{\mathrm{A}}$ from the quinol oxidases, and the relative ease of performing mutagenesis experiments, quinol oxidases have been useful in understanding cytochrome oxidases as well.

\section{X-Ray Crystal Structures}

The crystal structures of the 13-subunit bovine heart cytochrome $c$ oxidase in its oxidized, reduced, azide-bound, and carbon monoxide-bound forms $(120,121,145)$, and of the four-subunit enzyme from Paracoccus denitrificans in both oxidized and reduced forms $(55,64)$, have been published. In addition, structures of the complex of subunits I and II of the Paracoccus enzyme bound to an antibody fragment (97), and the water-soluble domain of subunit II of the $b a a_{3}$ oxidase from Thermus thermophilus (137), have also been reported. Figure 7 shows the structure of the redox centers and the location of several important amino acid residues in subunits I and II of the oxidized bovine enzyme. Except where noted, the structural description and amino acid numbering given in the text applies to this enzyme.

Subunit I contains 12 transmembrane helices arranged in a three-arm spiral pattern, with each arm consisting of four helices. These helices serve as a scaffold for the binding of heme $a$, heme $a_{3}$, and $\mathrm{Cu}_{\mathrm{B}}$; they also contain the ion channels used to conduct protons to the dioxygen-reduction site and to pump protons across the mitochondrial membrane. All three of the metal centers are at approximately the same depth in the membrane, about $13 \AA$ away from the cytoplasmic side. Heme $a$ is bound by $\mathrm{H} 61$ of helix II and $\mathrm{H} 378$ of helix X. The heme group is oriented such that the propionate moieties are directed roughly toward the cytoplasmic surface, with residues Y371, R438, and R439 at or near hydrogen-bonding distance. Heme $a_{3}$ contains a five-coordinate, high-spin iron bound by $\mathrm{H} 376$ of helix $\mathrm{X}$. The relative orientations of $\mathrm{H} 376$ and $\mathrm{H} 378$ place heme $a$ and heme $a_{3}$ on nearly opposite sides of helix X, yet the porphyrin planes of the hemes are oriented such that they come within $5 \AA$ of each other at their nearest approach, with an angle of $104^{\circ}$ between the two planes. As with heme $a$, heme $a_{3}$ has its propionate groups oriented toward the cytoplasmic side of the membrane, with hydrogen-bonding interactions between the propionates and residues W126 and D364. In the as-isolated enzyme, the sixth coordination site of the iron center of heme $a_{3}$ is vacant. 
The $\mathrm{Cu}_{\mathrm{B}}$ center, which lies $5 \AA$ away from heme $a_{3}$, is ligated by three histidine residues, H240 in helix VI and H290 and H291 in a short helix. The coordination geometry of the copper is trigonal, with the copper displaced out of the plane of the three nitrogen ligands toward heme $a_{3}$. H240 is covalently linked through its $\varepsilon^{2}$ nitrogen to the $\varepsilon^{1}$ carbon of Y244 to form a structure not observed to date in any protein except the cytochrome oxidases (and presumably the related quinol oxidases). This tyrosine is believed to be involved in both electron and proton transfer in this enzyme.

Subunit II of cytochrome oxidase consists of two transmembrane helices and a large extramembranous domain capping the enzyme. The soluble domain displays a cupredoxin fold motif (84) and contains the binuclear $\mathrm{Cu}_{\mathrm{A}}$ center. The two copper atoms in this center are bridged in a $\mu_{2}, \mu_{2}$ fashion by cysteines C196 and C200. For one of the two copper atoms, H161 and M207 complete the coordination sphere, while H204 and the carbonyl oxygen of E198 bind to the other copper atom. The coordination geometry of the copper atoms is best described as distorted trigonal pyramidal, with M207 and E198 as the apical ligands.

A magnesium ion was detected in the bovine enzyme, ligated by H368 and D369 of subunit I and E198 of subunit II. This ion was proposed to be part of a hydrogen-bond network linking $\mathrm{Cu}_{\mathrm{A}}$ and heme $a_{3}$ and may constitute part of either an electron transfer pathway or a gated ion channel through the enzyme.

Subunit III of cytochrome oxidase is composed mainly of seven transmembrane helices. This subunit is encoded in the mitochondrial DNA, and most bacterial cytochrome oxidases contain a homolog of this subunit. Modification of cytochrome oxidase with $N, N^{\prime}$-dicyclohexylcarbodiimide (DCCD), a reagent known to react at subunit III, or removal of subunit III during the protein purification process, disrupts proton translocation by this enzyme (99). However, the function of the subunit remains uncertain. Subunit III contains no metal centers and plays no direct role in catalysis. In addition, a two-subunit cytochrome oxidase lacking subunit III from $P$. denitrificans displays catalysis and proton pumping comparable to that of the beef heart enzyme in spite of the absence of subunit III (56), suggesting that the subunit is not tied intimately to the proton translocation mechanism of cytochrome oxidase.

The remaining subunits, IV-VIII, are encoded in the nuclear DNA, are not necessarily found in bacterial oxidases, and probably serve a regulatory function. Subunits IV, VIa, VIc, VIIa, VIIb, VIIc, and VIII are small, membrane-spanning subunits; subunits $\mathrm{Va}$ and $\mathrm{Vb}$ are extramembranous subunits on the matrix side of the mitochondrial membrane, and subunit VIb exists entirely on the cytosolic side of the membrane. Subunit $\mathrm{Vb}$ contains a zinc ion bound by four cysteine residues, which likely serves solely a structural role in the protein.

\section{Proton Channels Inferred from Crystal Structures}

From the three-dimensional structures of the bovine and Paracoccus cytochrome $c$ oxidase enzymes, in combination with the protein sequences of other cytochrome 
oxidases, putative channels for delivery of protons to the dioxygen reduction site and for pumping of protons across the membrane were proposed $(64,97,121,145)$. Three channels were deduced, the D channel, the K channel, and the $\mathrm{H}$ channel, named after the amino acid residues at the matrix side of these channels (D91, K319, and H413 in subunit I of the bovine enzyme, D124, K354, and H448 in the Paracoccus enzyme). The $\mathrm{K}$ channel extends from the matrix side of the protein to the dioxygen reduction center, whereas the $\mathrm{D}$ and $\mathrm{H}$ channels span the entire membrane. The full pathways are described elsewhere $(97,121)$. The key features of the amino acids lining these channels are the presence of protonatable side chains and the ability to form hydrogen bonds with nearby amino acids to form a network through the protein. As mentioned below, a few of these amino acids have been shown through mutagenesis studies to be crucial to proper enzyme function. However, a recent study suggests that the $\mathrm{H}$ channel is not involved in proton translocation (70).

\section{Mutagenesis Studies and Proton Translocation}

Most of the site-directed mutagenesis on cytochrome oxidase has been performed on the enzymes from Rhodobacter sphaeroides $(38,58,59,70,80)$ and $P$. denitrificans $(10,98,138)$. A large number of mutants from the related quinol oxidase from $E$. coli, cytochrome $b_{3}$, have been generated and studied as well (58). Mutants are typically assayed through measurements of the turnover of dioxygen in the enzyme and the ratio of protons pumped per electron travelling through the enzyme. For those mutants that retain some ability to catalyze electron transfer through the enzyme but show a decreased $\mathrm{H}^{+} / \mathrm{e}^{-}$ratio, decoupling of proton and electron transfer may occur through structural alterations in the protein that change the electron transfer pathways or from direct hindrance of proton transport. Residues whose mutations cause drastic effects on the movement of protons through the enzyme include D132, E286, T359, and K362 in subunit I $(R$. sphaeroides numbering). All of these are found in either the $\mathrm{D}$ or the $\mathrm{K}$ channel. Mutations of other residues produce small effects on protein structure and/or activity, but no conclusive role has been demonstrated with respect to active involvement in a proton channel. Even though these results may serve to define the proton conduits that may be involved in proton translocation, they do not pinpoint the sites at which protons cross the osmotic barrier during the proton translocation process.

\section{Comparison of the Crystal Structures of Reduced and Oxidized Cytochrome $c$ Oxidase}

To date, two crystal structures of fully reduced cytochrome $c$ oxidase have been reported, a $2.35 \AA$ resolution structure of the bovine enzyme (145) and a $3.3 \AA$ resolution structure of the enzyme from $P$. denitrificans (55). In the case of the Paracoccus enzyme, no significant structural changes were seen from the reduction of the enzyme when crystals of the oxidized enzyme were treated with dithionite. 
For the bovine enzyme, reduction resulted in a substantial conformational change of amino acids 49-55 in subunit I, particularly in the orientation of D51. In the oxidized form of the enzyme, this amino acid is buried in the protein, forming hydrogen bonds with S441 of subunit I and H204 and S205 of subunit II. In the reduced form of the enzyme, the carboxylate group of D51 is directed outward into the solvent, with only one hydrogen bond to S441. On the basis of this structural change, the role of D51 as the terminal amino acid of the proton-pumping channel was postulated. Aside from the changes in the amino acids surrounding D51, however, no other significant change in protein structure was observed for the reduced enzyme. Fully reduced enzyme is not believed to be a physiologically relevant state of the enzyme, so the structural details of reaction intermediates may vary from those observed in this structure.

\section{Redox-Linked Changes in Metal Environment and Protein Structure}

Redox-linked changes at the copper centers of cytochrome $c$ oxidase have been probed using X-ray absorption spectroscopy (XAS), a probe more sensitive than crystallography for determining interatomic distances. The water-soluble domain of subunit II in cytochrome $b a_{3}$, a cytochrome oxidase from $T$. thermophilus, was studied in its $\mathrm{Cu}(\mathrm{II}) / \mathrm{Cu}(\mathrm{I})$ and $\mathrm{Cu}(\mathrm{I}) / \mathrm{Cu}(\mathrm{I})$ states using extended $\mathrm{X}$-ray absorption fine structure spectroscopy. The coordination geometry around copper showed a small change upon reduction from the mixed-valence to the fully reduced form, with the copper-copper distance increasing from 2.43 to $2.51 \AA$, the average coppersulfur distance increasing from 2.29 to $2.33 \AA$, and the copper-histidine distances remaining essentially constant (13). An X-ray absorption study of the $\mathrm{Cu}_{\mathrm{B}}$ center of E. coli cytochrome $b_{3}$, a quinol oxidase that lacks the $\mathrm{Cu}_{\mathrm{A}}$ center, showed small changes in the copper histidine distances upon reduction, from three histidines each at $1.98 \AA$ to two histidines at $1.92 \AA$ and one at $2.10 \AA$ (104).

Although changes in the coordination environment of the heme $a$ moieties in cytochrome oxidase have not been determined through XAS, these changes are undoubtedly small. Heme $a$ remains six-coordinate, low-spin in both its oxidized and reduced forms, and thus its Fe-His distances are expected to remain essentially constant. Heme $a_{3}$ shows a high-spin/low-spin transition during the reaction cycle, which will affect the interaction of the heme with the axial histidine, but not to the extent of producing a significant conformational change in the protein backbone. As a result, the coordination geometry of the metal centers in the enzyme does not appear to change sufficiently upon simple oxidation/reduction to contribute to proton translocation under these conditions.

\section{Reaction of the Enzyme with Dioxygen}

The electron transfer from cytochrome $c$ to dioxygen provides the driving force for the translocation of protons across the mitochondrial membrane. The importance of this aspect of the reaction chemistry and the experimental accessibility of 


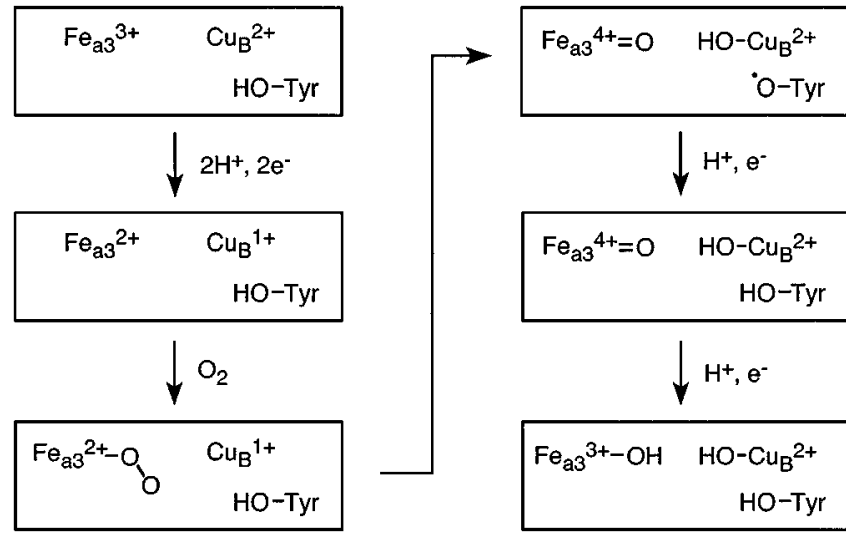

Figure 8 The dioxygen reduction cycle of cytochrome $c$ oxidase. The heme $a_{3}$ iron, $\mathrm{Cu}_{\mathrm{B}}$, and Y244 (bovine numbering) at the dioxygen binding site are shown.

this chemistry have led to a detailed description of the chemical transformations that take place in the reduction of dioxygen to water. The majority of the data concerning the dioxygen reaction cycle has come from flow-flash experiments, in which enzyme prepared in either two- or four-electron reduced states and bound with carbon monoxide is subjected to a laser pulse in order to displace the $\mathrm{CO}$ and initiate dioxygen reduction chemistry. Several intermediates in this cycle have been generated using alternative methods, such as reaction of oxidized enzyme with hydrogen peroxide, reversal of electron transfer using highly energized membranes, stopped-flow and freeze-quench techniques, and the reaction of partially or fully reduced enzyme with dioxygen at low temperatures to trap the intermediates. These intermediates have been studied extensively using optical, resonance Raman, electron paramagnetic resonance(EPR), and infrared spectroscopy, as well as other techniques.

The current understanding of the dioxygen reduction pathway under physiological conditions is shown in Figure 8. Prior to the binding of dioxygen, two electrons are transferred from ferrocytochrome $c$ to the binuclear center of the enzyme. Reaction of the two-electron-reduced enzyme with dioxygen leads to the formation of a ferrous-oxy species known as intermediate A (Compound A). This species has been observed in flow-flash resonance Raman experiments using both fully reduced and mixed valence cytochrome oxidase $(52,53,90,126,127)$. It is characterized by a peak at $571 \mathrm{~cm}^{-1}$ in the resonance Raman spectrum and a very small shift in the Soret band in the absorption difference spectrum (versus reduced enzyme). Species A then reacts further to yield intermediate $\mathrm{P}$ (Compound $\mathrm{C}$, peroxo form), originally assumed to be a peroxo species. This form has also been generated independently from the addition of hydrogen peroxide to oxidized or reduced enzyme $(12,140,141)$, or by the partial reversal of dioxygen chemistry under conditions of high thermodynamic driving force in the reverse direction 
$(134,136)$. It is characterized by an absorption maximum at $607 \mathrm{~nm}$ in the optical difference spectrum of the enzyme. Resonance Raman spectroscopy has suggested the presence of an oxoferryl species rather than a peroxide at this reduction level, on account of a band at $804 \mathrm{~cm}^{-1}$ that does not display the isotopic behavior of a bound peroxide $(88,100)$. Based on the current state of knowledge, it appears that the modified tyrosine (Y244) acts as an electron donor at this point to reduce a transient peroxide and form a tyrosyl radical, oxyferryl heme $a_{3}$ and a $\mathrm{Cu}_{\mathrm{B}}$ (II)hydroxide species through a coupled proton/electron transfer. Addition of a third electron from ferrocytochrome $c$ yields species $\mathrm{F}$, the ferryl form of the enzyme. This species has a band in the optical absorption difference spectrum at $580 \mathrm{~nm}$ $(134,139,140)$ and shows an Fe(IV)-oxo stretch in the resonance Raman spectrum at $785 \mathrm{~cm}^{-1}(51,89,125)$. Given the participation of the tyrosyl radical at Y244, the electron used to form the F intermediate likely reduces the tyrosyl radical back to tyrosine. Addition of a fourth electron to the dioxygen binding sites leads to the reduction of the oxyferryl group to water, forming species $\mathrm{O}$ and completing the reaction cycle.

Early low-temperature studies of cytochrome oxidase led to the identification and characterization of Compound A $(23,25)$, Compound $\mathrm{C}(14,23,24)$, and two forms of the three-electron reduced intermediate $\mathrm{F}(14,65)$. Notable in these studies was the observation of dioxygen $\mathrm{O}-\mathrm{O}$ bond cleavage at the three-electron reduction level (14). In addition, low-temperature studies never resolved the presence of a radical species associated with the $\mathrm{P}$ intermediate. Therefore, it is likely the case that the $\mathrm{P}$ intermediate formed at low temperature remains as an intact peroxide species. As a result, although the dioxygen chemistry of cytochrome oxidase at low temperature generally parallels that at room temperature, low-temperature conditions do not yield a completely accurate description of physiological enzyme turnover.

\section{Redox-Coupled Proton Uptake by Cytochrome Oxidase}

Heme $a$, heme $a_{3}$, and $\mathrm{Cu}_{\mathrm{B}}$ in cytochrome oxidase have $\mathrm{pH}$-dependent redox potentials, and thus changes in protonation state of the enzyme are expected to occur upon reduction. Through the use of $\mathrm{pH}$ indicators, the $\mathrm{pH}$ changes that occur as a result of redox changes in cytochrome oxidase have been measured. In the full reduction of enzyme, $2-2.5 \mathrm{H}^{+}$are taken up by the enzyme $(22,83)$. The reduction of cyanide-bound enzyme results in the uptake of 1-1.5 protons (heme $a_{3}$ remains oxidized) $(22,83)$. The reduction of CO-bound, mixed-valence cytochrome oxidase (heme $a_{3}, \mathrm{Cu}_{\mathrm{B}}$ reduced) is accompanied by the uptake of $0.76 \mathrm{H}^{+}(22)$. Binding of dioxygen or carbon monoxide to reduced enzyme is not associated with proton uptake or release (83). Finally, the conversions of $\mathrm{O} \rightarrow \mathrm{P}$ and $\mathrm{O} \rightarrow \mathrm{F}$ in the forward direction are accompanied by the uptake of 2 and 3 protons, respectively (82). In general, the passing of electrons to the binuclear center of the enzyme appears to be coupled with the uptake of an equal number of protons; this electroneutrality principle likely applies all throughout the reaction cycle. In terms of the proton pumping of the enzyme, the $1: 1$ ratio of proton uptake 
to electron transfer to the binuclear center suggests that there is no storage of protons in the enzyme during the proton pumping cycle. Rather, there is likely just a chain of proton carriers through the enzyme, and proton pumping consists of protons hopping roughly in concert along a chain of hydrogen bonds. The energy transduction consists of altering the orientation of the hydrogen bonds, changing the $\mathrm{pK}_{\mathrm{a}}$ 's of the amino acid residues, and transiently removing and restoring the osmotic barrier.

\section{Thermodynamics of Electron Transfer}

Ultimately, the amount of energy available for pumping protons through cytochrome oxidase is determined by the reduction potentials of the substrates and protein-bound redox centers involved in enzyme turnover. The reduction potential for cytochrome $c$ is approximately $250 \mathrm{mV}$. In cytochrome oxidase, measurements of redox potential are complicated by redox cooperativity and difficulty in probing the $\mathrm{Cu}_{\mathrm{B}}$ site. Nevertheless, reduction potentials of approximately 290, 290, 340, and $340 \mathrm{mV}$ for $\mathrm{Cu}_{\mathrm{A}}$, heme $a$, heme $a_{3}$, and $\mathrm{Cu}_{\mathrm{B}}$, respectively, have been estimated for the resting enzyme (85). The reduction potential for the four-electron reduction of dioxygen to water is $815 \mathrm{mV}$ at $\mathrm{pH} 7$ under standard conditions, whereas the two-electron $\mathrm{O}_{2} / \mathrm{H}_{2} \mathrm{O}_{2}$ and $\mathrm{H}_{2} \mathrm{O}_{2} / \mathrm{H}_{2} \mathrm{O}$ couples have reduction potentials of $280 \mathrm{mV}$ and $1350 \mathrm{mV}$ respectively. Even though the latter two potentials are altered in cytochrome oxidase on account of dioxygen binding to the heme-copper site, it is nevertheless clear that reduction of dioxygen to peroxide cannot provide significant energy for translocating protons. This has been verified in studies of the reaction of cytochrome oxidase with hydrogen peroxide as the terminal electron acceptor, in which as many as four protons are translocated through the enzyme during the reduction of peroxide to water $(71,78,79,129)$. Thus, cleavage of the $\mathrm{O}-\mathrm{O}$ bond of peroxide to form the $\mathrm{P}$ intermediate, and the $\mathrm{P} \rightarrow \mathrm{F}$ and $\mathrm{F} \rightarrow \mathrm{O}$ transitions, are the only steps in the reaction cycle in which free energy can be transduced into proton translocation. On the basis of ATP-driven reverse electron transfer in this enzyme, Wikström (135) determined that the $\mathrm{P} \rightarrow \mathrm{F}$ and $\mathrm{F} \rightarrow \mathrm{O}$ transitions were each coupled to the translocation of two protons across the membrane, and therefore that these are the only two energy transduction steps in proton pumping. Using this $2 \mathrm{H}^{+} / 1 \mathrm{e}^{-}$stoichiometry, the reduction potentials of the $\mathrm{P}$ and $\mathrm{F}$ intermediates were measured as 1220 and $1050 \mathrm{mV}$, respectively, and the binding of dioxygen to the two-electron reduced enzyme and formation of the $\mathrm{P}$ intermediate was calculated to involve a free energy change of $-5 \mathrm{kcal} / \mathrm{mol}$ (136).

Both the $\mathrm{P}$ and $\mathrm{F}$ intermediates appear to contain heme $a_{3}$ in its oxyferryl form, and $\mathrm{Cu}_{\mathrm{B}}$ in its $2+$ oxidation state with a presumed hydroxide ion bound to the open coordination site on the copper. The only difference in the redox centers between the $\mathrm{P}$ and $\mathrm{F}$ intermediates is the presence or absence of the tyrosyl radical. Notably, the $\mathrm{O}-\mathrm{O}$ bond of dioxygen is broken in both intermediates, suggesting that $\mathrm{O}-\mathrm{O}$ bond cleavage does not provide the principal means of inducing the redox-linked conformational changes required for proton pumping. Nevertheless, 
$\mathrm{O}-\mathrm{O}$ bond cleavage must promote conformational changes within the enzyme that allow the subsequent electron transfers through the enzyme to be coupled to proton translocation.

Given that cytochrome $c$ binding does not provide energy for proton pumping, and that the metal coordination geometries do not change significantly upon reduction, the conformational changes necessary to promote proton pumping must arise from the effect of the charge of the redox centers on the rest of the protein along with the contribution of dioxygen bond cleavage. It is noteworthy that the oxyferryl group is capable of participating in electrostatic interactions, whereas the tyrosyl radical is electroneutral. Formation of the tyrosyl radical, however, will alter a hydrogen-bonding network. In addition, because of the difference in location and chemical properties of the tyrosyl radical and the oxyferryl group, the two electron transfers that promote proton pumping would seem to be highly asymmetrical in terms of how the redox processes at these centers couple to proton translocation. A possible resolution to this discrepancy is that the $\mathrm{F} \rightarrow \mathrm{O}$ transition may involve a pre-equilibrium in which a formal hydrogen atom transfer from Y244 to the oxyferryl group creates ferric heme $a_{3}$ and a tyrosyl radical, at which point an electron transfer to the tyrosyl radical can occur and couple to proton pumping. Transient formation of a ferric heme $a_{3} / \mathrm{Y} 244$ radical state during the $\mathrm{P} \rightarrow \mathrm{F}$ transition could also provide greater symmetry of the two electron transfers. Alternatively, it may be the case that the enzyme merely requires a high potential redox center to accept an electron and that the precise chemical nature of the electron acceptor is of minor importance with respect to proton pumping.

A theoretical treatment of the thermodynamics of redox linkage in cytochrome oxidase has been presented previously (85). Key to the operation of a redoxlinked pump is the fact that energy transduction occurs in the form of electron transfers as well as conformational changes in the protein that are not associated with the reorganization energy of the electron transfers. Within an ionchannel-based proton pump such as cytochrome oxidase, electron transfers are weakly coupled to protein movement and thus do not promote proton pumping directly. Rather, the electron transfers transduce energy into the protein backbone, and subsequent relaxation of the protein performs the proton pumping. In an analogy with Marcus theory, the energy landscape for protein conformational changes can be represented by parabolic curves in a dimension referred to as the nuclear coordinate. In this way, the energy landscape traversed by the protein during proton pumping can be represented by a three-dimensional plot, in which one axis corresponds to motion associated with electron transfer, and the other axis corresponds to motion along the nuclear coordinate. A generalized energy landscape is depicted in Figure 9. In general, energy released during movement along the electron transfer axis is lost as heat, whereas the energy drops along the nuclear coordinate represent free energy available for proton translocation. Understanding the proton pumping in cytochrome $c$ oxidase requires a physical description of these transitions, particularly those along the nuclear coordinate. 

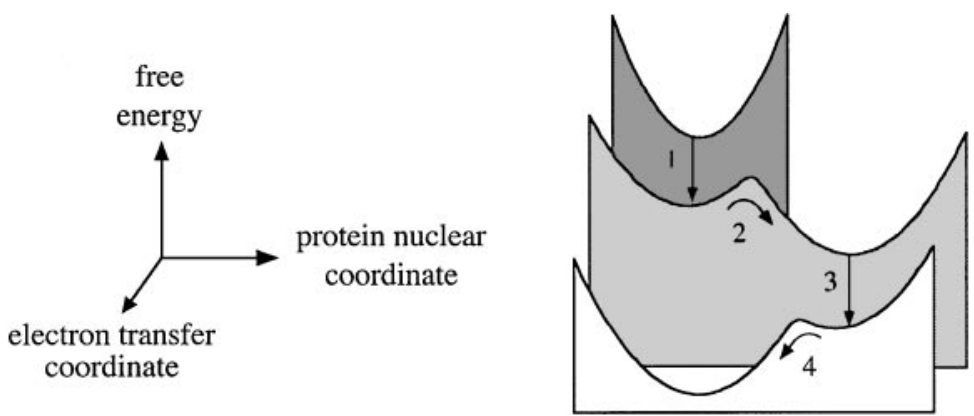

Figure 9 Generalized energy landscape for a redox-linked proton pump. (1) Electron input. (2) Protein conformational change coupled to proton pumping. (3) Internal electron transfer or electron output. (4) Protein relaxation coupled to proton pumping.

\section{Prospects for Further Understanding of the Enzyme}

Much of the chemistry of cytochrome oxidase is well understood. The enzyme structure is known, the dioxygen chemistry has been defined, the sequence of electron carriers has been established, the thermodynamics of electron transfer are well defined, and a theoretical framework for understanding redox linkage is in place. In spite of this wealth of knowledge, the actual chemical and structural details of the proton pumping process itself are still unknown. Such knowledge requires structural definition of the protein in its intermediate states in greater breadth and depth than is currently available. Detailed description of the protein structure in the $\mathrm{P}$ and $\mathrm{F}$ forms is of particular importance. A picture of the transitions between conformational states that lead to vectorial proton pumping is also necessary to complete a mechanistic description of this enzyme.

\section{NADH:UBIQUINONE OXIDOREDUCTASE: A Proton Pump with an Unknown Mechanism}

NADH:ubiquinone oxidoreductase utilizes NADH formed during glycolysis and the TCA cycle in the first of the proton pumps in the respiratory chain $(37,130,131)$. The reaction of this enzyme is shown in Equation 4. The electron transfer from NADH to ubiquinone is coupled to the translocation of protons, with an accepted proton-pumping stoichiometry of $2 \mathrm{H}^{+} / \mathrm{e}^{-}$transferred through the protein. The proton uptake shown in Equation 4 involves protons that were initially released in the TCA cycle.

$$
\mathrm{NADH}+\mathrm{H}^{+}+\mathrm{Q} \rightarrow \mathrm{NAD}^{+}+\mathrm{QH}_{2}
$$

Mitochondrial Complex I is a very large enzyme. The bovine complex contains at least 43 subunits and has a molecular weight greater than 900,000 (20). 
Figure 10 Schematic diagram of Complex I showing approximate locations of redox centers.

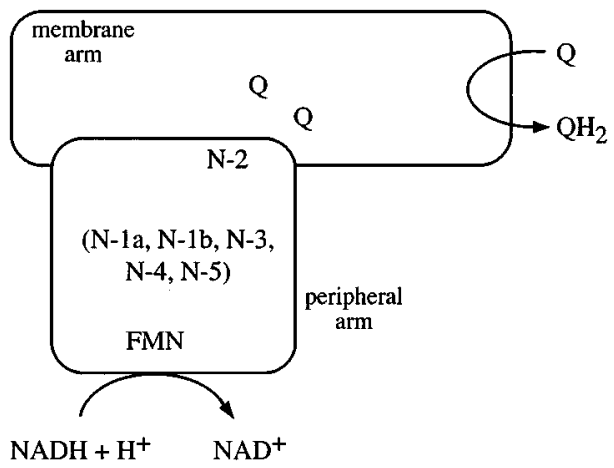

Seven of the subunits (ND1-ND6, ND4L) are encoded in the mitochondrial DNA with the remainder encoded in the nucleus. The enzyme contains a noncovalently bound flavin mononucleotide (FMN) molecule, as many as nine iron-sulfur clusters, and at least two ubiquinone binding sites. A schematic diagram of the enzyme is shown in Figure 10. Analysis of the enzyme has been aided by the presence of smaller, homologous enzymes in bacteria. Gene clusters of proton-translocating NADH:quinone oxidoreductases from the bacteria P. denitrificans (143), E. coli (133), Rhodobacter capsulatus (33), and T. thermophilus HB-8 (144) have been sequenced fully. These enzymes contain fourteen subunits, seven of which correspond to the bovine subunits encoded in the mitochondrial DNA, and the remainder of which all have homologs in the bovine enzyme. The molecular weight of the bacterial enzymes is approximately 530,000.

\section{Structure of the Complex}

The most detailed description to date of the overall protein structure of Complex I comes from electron microscopy of the enzymes from the fungus Neurospora crass $a$ and the bacterium $E$. coli $(48,49,57)$. The two enzymes are very similar in appearance in spite of a large difference in molecular weights for these enzymes (900,000 for the fungal enzyme, 530,000 for the bacterial enzyme). The structure of the $N$. crassa enzyme is shown in Figure 1. The enzyme is L-shaped, with one arm lying within the mitochondrial membrane and the other arm protruding into the matrix space. In the $N$. crassa enzyme, the membrane arm is approximately $20 \mathrm{~nm}$ long and the peripheral arm extends $8 \mathrm{~nm}$ out from the membrane. In the $E$. coli enzyme, the membrane arm is slightly shorter, but the peripheral arm is approximately the same length as that of the $N$. crassa enzyme. Most of the additional mass of the $N$. crassa enzyme occurs around the membrane arm and at the junction of the membrane and peripheral arms, with the additional subunits apparently providing greater stability of the enzyme as compared to that from E. coli. 


\section{Subunit Description and Localization of Prosthetic Groups}

A useful description of Complex I arises from the fact the enzyme can be separated into distinct subunit fractions upon exposure to certain reagents. Treatment of bovine Complex I with perchlorate leads to the breakup of the complex into three fragments: a water-soluble flavoprotein fragment (FP), a water-soluble iron protein (IP), and a hydrophobic protein fraction (HP) $(45,101-103)$. The flavoprotein fragment contains the FMN, an $\mathrm{Fe}_{2} \mathrm{~S}_{2}$ cluster, and an $\mathrm{Fe}_{4} \mathrm{~S}_{4}$ cluster. The iron protein contains most if not all of the remaining iron in the enzyme, whereas the hydrophobic protein consists mostly of membrane-bound subunits. Of particular importance is the fact that the two extramembranous fractions contain all of the fixed redox centers in the enzyme, whereas the membrane-spanning subunits are devoid of redox centers. The two hydrophilic fragments lie within the matrix space and appear to constitute the peripheral arm of the enzyme as described above.

If Complex I is treated with the detergent $N, N$-dimethyldodecylamine $N$-oxide, it can be separated into two fractions termed $\mathrm{I} \alpha$ and $\mathrm{I} \beta$ (41). Fragment $\mathrm{I} \alpha$ consists of the FP and IP fractions, in addition to some of the membrane-bound subunits. This fragment is capable of catalyzing electron transfer from NADH to ubiquinone-1, but it is not certain whether this fragment is competent to translocate protons when reinserted into a membrane. Fragment $\mathrm{I} \beta$ consists solely of hydrophobic subunits and shows no catalytic activity. Sucrose-gradient centrifugation of the fragment $\alpha$ leads to the isolation of a smaller subcomplex termed $\mathrm{I} \lambda$, in which the remaining hydrophobic subunits have been removed (40). This subcomplex maintains its electron transfer activity with respect to ubiquinone-1, but shows a much slower reduction rate for decylubiquinone.

In a similar manner, the E. coli NADH:ubiquinone oxidoreductase has been fractioned into three fragments (72). An NADH dehyrogenase fragment consists of three hydrophilic subunits, in which FMN and five iron-sulfur clusters are believed to be bound. An amphipathic fragment composed of four subunits contains the remaining iron-sulfur clusters, and a hydrophobic fragment, consisting of the seven subunits homologous to the mitochondrially encoded subunits of the bovine enzyme, contains ubiquinone binding sites.

\section{The Iron-Sulfur Clusters}

A comparison of mammalian and bacterial NADH:quinone oxidoreductases for which a complete DNA sequence is known shows the presence of 32 strictly conserved cysteine residues, which allows the binding of eight iron-sulfur clusters. These iron-sulfur cluster sites are found only in the hydrophilic enzyme subunits. In addition, four additional conserved cysteines in the enzymes from E. coli, T. thermophilus, and Salmonella typhimurium (8) suggest the presence of a ninth iron-sulfur cluster in these enzymes. Six EPR signals have been assigned to ironsulfur clusters in this enzyme. The clusters associated with these signals are termed N-1a $\left(\mathrm{Fe}_{2} \mathrm{~S}_{2}\right), \mathrm{N}-1 \mathrm{~b}\left(\mathrm{Fe}_{2} \mathrm{~S}_{2}\right), \mathrm{N}-2\left(\mathrm{Fe}_{4} \mathrm{~S}_{4}\right), \mathrm{N}-3\left(\mathrm{Fe}_{4} \mathrm{~S}_{4}\right), \mathrm{N}-4\left(\mathrm{Fe}_{4} \mathrm{~S}_{4}\right)$, and N-5 $\left(\mathrm{Fe}_{4} \mathrm{~S}_{4}\right)$ 
(91). Only N-1b, N-2, N-3, and N-4 have been observed universally in protonpumping NADH:quinone oxidoreductases. In addition, an $\mathrm{Fe}_{2} \mathrm{~S}_{2}$ cluster labeled $\mathrm{N}-1 \mathrm{c}$ has been observed in preparations of E. coli Complex I (72).

The N-2 cluster appears to be located near the interface of the hydrophilic and hydrophobic fragments of Complex I. Evidence for this location comes from the observation that the bovine I $\lambda$ fragment displays a disrupted EPR spectrum for the N-2 cluster with respect to that in the holoenzyme, whereas the remaining EPR-detectable clusters remain unchanged (40). In addition, the fungus $N$. crassa produces a small form of Complex I that lacks the membrane-bound subunits when chloramphenicol is used to inhibit protein synthesis from the mitochondrial DNA. This small form catalyzes electron transfer from NADH to ubiquinone, but lacks the $\mathrm{N}-2$ center $(43,132)$. As further evidence for its location, the N-2 cluster appears to interact magnetically with ubisemiquinone in the membrane-bound fraction of Complex I, as described below.

\section{The Ubiquinone Binding Sites}

In accord with the hydrophobic nature of ubiquinone-10, the binding sites for this substrate are found in the membrane-bound fraction of the enzyme. Inhibition of Complex I by compounds such as rotenone and piericidin-A occurs through the prevention of electron transfer from $\mathrm{N}-2$ to ubiquinone by disrupting the binding of quinone to the catalytic sites. Through the use of tritiated dihydrorotenone, which is able to photocrosslink to the enzyme, the rotenone binding site was localized to subunit ND1 (35), implying that ubiquinone binding also occurs at this subunit. It is worth noting that ND1 was identified as a subunit in fragment $\mathrm{I} \alpha$, a fragment capable of NADH:ubiquinone oxidoreductase activity.

The presence of (at least) two ubiquinone binding sites has been deduced from several lines of evidence. The onset of inhibition of Complex I in submitochondrial particles by N-methyl-4-phenylpyridinium $\left(\mathrm{MPP}^{+}\right)$was shown to be biphasic (112). Also, the presence of both competitive and noncompetitive inhibition modes for several Complex I inhibitors suggests the presence of two sites (44). Dual binding sites have also been postulated on the basis of the differences in reaction kinetics and proton pumping by various ubiquinone analogs (31). EPR studies of energized submitochondrial particles have shown the presence of two semiquinone radical signals associated with Complex I, one of which is eliminated in the presence of respiratory decouplers. Both signals are decreased in the presence of rotenone, but show different inhibition behavior, demonstrating that the signals truly arise from different sites and not from different states of the enzyme. These signals are also distinguishable on the basis of their relaxation behavior, in that one is considered a slow-relaxing species while the other relaxes more rapidly (128). A splitting of the $g=2.05$ signal of center $\mathrm{N}-2$ has been postulated to arise from interaction of the iron-sulfur with a semiquinone at an interspin distance of 8-11 $\AA$, but this splitting has also been interpreted in terms of a model in which the N-2 EPR signal arises from two interacting iron-sulfur clusters (122). 


\section{Thermodynamics of Proton Translocation}

The energetics of proton pumping are dictated by the reduction potentials of $\mathrm{NAD}^{+}$ and ubiquinone, $-320 \mathrm{mV}$ and $+60 \mathrm{mV}$ respectively. Using the stoichiometry of Equation 4, the transfer of two electrons from NADH to ubiquinone is associated with a release of $760 \mathrm{meV}$ of energy under standard conditions. With a protonmotive force $(\Delta \psi-2.3 R T \Delta \mathrm{pH} / F)$ of $200 \mathrm{mV}$ across the inner mitochondrial membrane and a $2 \mathrm{H}^{+} / 1 \mathrm{e}^{-}$proton-pumping stoichiometry, an energetic barrier of 800 $\mathrm{meV}$ must be overcome in order to promote the requisite proton pumping. Thus, the enzyme must operate at a high $([\mathrm{NADH}][\mathrm{Q}]) /\left(\left[\mathrm{NAD}^{+}\right]\left[\mathrm{QH}_{2}\right]\right)$ ratio, and the coupling between the electron and proton transfer must be strong in order for efficient proton pumping to occur in a nearly thermoneutral reaction.

The redox centers in the enzyme and their associated reduction potentials are FMN (-340 mV), N-1a $(-370 \mathrm{mV}), \mathrm{N}-5$ (-260 mV), N-1b (-250 mV), N-3 $(-250 \mathrm{mV}), \mathrm{N}-4(-250 \mathrm{mV})$, and N-2 $(-150 \mathrm{mV})(61,113,114)$. The intermediate reduction potential of $\mathrm{N}-2$ with respect to $\mathrm{NAD}^{+}$and ubiquinone has led to the suggestion that one proton is translocated across the membrane during the electron transfer from NADH to N-2, and the second proton translocation is associated with the electron transfer from $\mathrm{N}-2$ to ubiquinone. The reduction potentials of centers $\mathrm{N}-1 \mathrm{a}$ and $\mathrm{N}-2$ show a $60 \mathrm{mV} / \mathrm{pH}$ unit dependence (61), suggesting that proton-coupled redox processes at these sites may play a role in the proton translocation.

\section{Electron Transfer}

The kinetics of the individual electron transfers from NADH through the redox centers of Complex I have not been measured successfully to date because the electron transfers occur on a time scale less than $5 \mathrm{~ms}$, the dead time of freezequench EPR techniques $(6,9,95)$. Thus, the electron transfer pathway(s) through the enzyme remains speculative. However, based on the topology of the enzyme, studies of the reactivity of the subcomplexes of the enzyme, and the reduction potentials of the redox centers, a likely set of electron transfers through the enzyme is $\mathrm{NADH} \rightarrow \mathrm{FMN} \rightarrow(\mathrm{N}-5, \mathrm{~N}-1 \mathrm{~b}, \mathrm{~N}-3, \mathrm{~N}-4) \rightarrow \mathrm{N}-2 \rightarrow$ ubiquinone, where the isopotential iron-sulfur clusters could act as a linear series of redox centers or could equilibrate to form a reservoir of electrons. As the electron transfer through the enzyme is coupled to proton translocation, a lack of detail concerning the electron transfers constitutes a significant barrier to understanding proton pumping by this enzyme.

\section{Details of Proton Pumping}

Given the incomplete structural and chemical information to date regarding Complex I, a detailed understanding of the proton pumping in this enzyme has not been achieved. Mechanistic models of proton translocation have been proposed $(17,34)$, but they currently lack experimental backing. Important details that need 
to be resolved with respect to proton pumping include the atomic level structure of the enzyme, the true sequence of electron carriers in the enzyme and the rates of electron transfer between the centers, the number of ubiquinone binding sites, the location of proton channels in the complex, and whether or not a small molecule (ubiquinone) acts as a diffusable proton carrier in the enzyme.

In addition to these issues, two important questions regarding energy transduction remain to be understood. First, although the potential gradient that must be overcome in proton pumping extends across the mitochondrial membrane, most of the redox centers in Complex I reside in the extramembranous arm of the protein complex. Thus, there must be a means of communicating the redox changes in the peripheral arm of the enzyme to the membrane arm where the proton translocation actually occurs. The second issue relates both to redox linkage and to proton gating. In the presence of a potential gradient across the mitochondrial membrane, the turnover of the enzyme and the associated proton pumping constitutes a nearly thermoneutral reaction. Given these thermodynamics, one would expect significant proton slippage in this enzyme, in that decoupling of proton transfer from electron transfer yields a more thermodynamically favorable process. Because there are few redox centers within the membrane space, it is unclear how electrostatic interactions within the membrane itself prevent both the backflow of protons and the uncoupling of proton and electron transfer. These two issues are the fundamental conceptual problems in understanding the proton translocation by this enzyme.

Given the near-thermoneutrality of proton pumping in Complex I, it is likely that the proton translocation involves a small molecule as a proton carrier, as this type of mechanism removes the possibility of proton slippage decreasing the efficiency of the enzyme. However, a Q-cycle cannot occur in this enzyme because NADH is the electron donor rather than ubiquinol. The large number of electron carriers and quinone binding sites in the complex are consistent with branched electron transfer pathways and redox processes occurring at more than one quinone binding site, features expected for small-molecule-based proton translocation. These possibilities are commonly incorporated into proton-pumping models for the enzyme $(17,34)$.

\section{SUCCINATE:UBIQUINONE OXIDOREDUCTASE: A Respiratory Enzyme That Does Not Pump Protons}

Succinate:ubiquinone oxidoreductase (SQR) operates in both the respiratory chain and the TCA cycle, oxidizing succinate to fumarate and transferring the electrons from succinate to ubiquinone, according to Equation $5(4,50)$. The reaction of this enzyme is reversible, such that the direction of electron flow through the enzyme is dictated by the relative concentrations of reactants and products. SQR is not a proton pump, but it does serve as an entry point for electrons into the respiratory 
chain and as a site for regulation of the activity of the TCA cycle.

$$
\text { succinate }+\mathrm{Q} \rightarrow \text { fumarate }+\mathrm{QH}_{2}
$$

Mammalian SQR is a four-subunit enzyme with a molecular weight of 125,000. The two largest subunits are extramembranous subunits that lie in the matrix space. A $79 \mathrm{kDa}$ flavoprotein contains a covalently bound flavin adenine dinucleotide (FAD), and a $27 \mathrm{kDa}$ iron-sulfur protein binds three iron-sulfur clusters: an $\mathrm{Fe}_{2} \mathrm{~S}_{2}$ center (S-1), an $\mathrm{Fe}_{4} \mathrm{~S}_{4}$ cluster (S-2), and an $\mathrm{Fe}_{3} \mathrm{~S}_{4}$ center (S-3). The two remaining subunits are membrane-bound. These subunits bind a single low-spin $b$ heme at a site not yet fully determined and have at least two ubiquinone/ubiquinol binding sites. The presence of two magnetically interacting ubisemiquinone species has been observed in partially reduced bovine enzyme through the use of EPR spectroscopy (106).

$\mathrm{SQR}$ is a member of a family of enzymes catalyzing the transfer of electrons between succinate and quinones, a family that includes the quinol:fumarate oxidoreductase (QFR) enzymes. Enzymes in this family have highly conserved flavoprotein and iron-sulfur protein subunits. The membrane-bound subunits show topological similarity but vary significantly in amino acid sequence, and additional variability occurs in heme content, reduction potentials of the heme groups, identity of the quinol substrate, and quinol/quinone binding sites. On account of the strong similarities among the enzymes, a direct comparison between SQR and QFR enzymes is useful. Two crystal structures of quinol:fumarate oxidoreductases, from E. coli (62) and Wolinella succinogenes (69), have been reported recently. In that no crystal structure of mitochondrial SQR has been reported, emphasis is placed on the QFR enzymes as structural references for understanding the operation of SQR.

\section{QFR Crystal Structures}

Crystal structures of the QFR enzymes from E. coli and Wolinella succinogenes have been solved at resolutions of $3.3 \AA$ and $2.2 \AA$, respectively $(62,69)$, and are shown in Figure 11. The E. coli enzyme resides within the cytoplasmic membrane with its extramembranous subunits in the cytoplasmic space. Menaquinol is the electron donor for this enzyme. As with mitochondrial SQR, the E. coli QFR consists of a flavoprotein subunit, an iron-sulfur protein containing three ironsulfur clusters, and two membrane-bound subunits. It has a total molecular weight of 128,000 . The flavoprotein (FrdA) displays a Rossman fold characteristic of FAD-binding proteins, with FAD bound to the $\mathrm{N}-\varepsilon$ nitrogen of $\mathrm{H} 44$ through a covalent linkage with carbon C-8a. The inhibitor oxaloacetate binds in a polar region adjacent to the flavin, interacting with residues T244, E245, R287, G392, and $\mathrm{H} 355$.

The iron-sulfur protein (FrdB) lies between the flavoprotein and the membranebound subunits. This subunit binds its three iron-sulfur clusters in a nearly linear 
array. Center S-1 is bound through residues C57, C62, C65, and C77 in a domain similar to that of $\mathrm{Fe}_{2} \mathrm{~S}_{2}$-containing ferredoxins. Center $\mathrm{S}-2$ is bound by $\mathrm{C} 148, \mathrm{C} 151$, $\mathrm{C} 154$, and $\mathrm{C} 214$, whereas S-3 is bound by $\mathrm{C} 158, \mathrm{C} 204$, and $\mathrm{C} 210$. The domain containing these two clusters is reminiscent of $\mathrm{Fe}_{4} \mathrm{~S}_{4}$-containing ferredoxins.

Two membrane-bound subunits, FrdC and FrdD, complete the structure of the enzyme. Each of these subunits consists of three transmembrane helices connected by loop regions. The helices are labeled I-III (FrdC) and IV-VI (FrdD). Two molecules of menaquinone (a product of enzyme turnover) were bound in this transmembrane region. One molecule, $\mathrm{Q}_{\mathrm{P}}(\mathrm{P}=$ proximal $)$, is bound near the cytoplasmic side of the membrane near the iron-sulfur subunit. The binding pocket for this quinone is formed from helices I, II, IV, and V. Residue R28 of the FrdC subunit and the carbonyl of C204 of the iron-sulfur protein are close enough to the menaquinone to participate in hydrogen-bonding interactions with the oxygen atoms of the quinone or with the hydroxyl groups of the quinol. In addition, the side chain of R81 of FrdC lies within $4 \AA$ of one of the oxygen atoms of menaquinone. It is likely that the two arginine residues are capable of stabilizing a semiquinone anion or a deprotonated quinol at this site. The second molecule of menaquinone, $\mathrm{Q}_{\mathrm{D}}$ (distal), is bound near the periplasmic side of the membrane. The quinone molecule lies in a hydrophobic pocket formed from residues from helices I, II, IV, and $\mathrm{V}$.

The arrangement of redox centers through the enzyme is nearly linear in the order $\mathrm{Q}_{\mathrm{D}}, \mathrm{Q}_{\mathrm{P}}, \mathrm{S}-3, \mathrm{~S}-2, \mathrm{~S}-1$, and FAD. Center-to-center distances between these redox centers are $27 \AA\left(\mathrm{Q}_{\mathrm{D}} \rightarrow \mathrm{Q}_{\mathrm{P}}\right), 11 \AA\left(\mathrm{Q}_{\mathrm{P}} \rightarrow \mathrm{S}-3\right), 13 \AA(\mathrm{S}-3 \rightarrow \mathrm{S}-2), 14 \AA$ $(\mathrm{S}-2 \rightarrow \mathrm{S}-1)$, and $13 \AA$ (S-1 $\rightarrow$ FAD). On the basis of these distances, an electron transfer chain from $Q_{P}$ to $F A D$ is both viable and consistent with the known enzymology of the enzyme. The $27 \AA$ distance between the two quinones suggests that electron transfer between the two is not viable. In addition, the hydrophobic environment around the $\mathrm{Q}_{\mathrm{D}}$ site is incompatible with redox processes occurring at $\mathrm{Q}_{\mathrm{D}}$.

The Wolinella succinogenes enzyme, with a molecular weight of 130,000 , contains three subunits: the flavoprotein subunit, iron-sulfur protein, and one transmembrane subunit (69). The flavoprotein and iron-sulfur subunits are homologous to those of the $E$. coli enzyme and are very similar structurally. The membrane subunit consists of five helices labeled I, II, IV, V, and VI. In contrast to the E. coli enzyme, this subunit contains two heme groups, $b_{\mathrm{P}}$ and $b_{\mathrm{D}}$. Heme $b_{\mathrm{P}}$ is bound by residues $\mathrm{H} 93$ (helix II) and $\mathrm{H} 182$ (helix V), and heme $b_{\mathrm{D}}$ is bound by H44 (helix I) and H143 (helix IV). The porphyrin planes of the two heme groups are both parallel to the membrane normal, but they are nearly perpendicular with respect to each other. The edges of the heme groups are less than $5 \AA$ apart at their nearest approach, and a propionate of heme $b_{\mathrm{P}}$ is approximately $9 \AA$ away from center S-3. Finally, no quinone molecules were detected in the Wolinella succinogenes enzyme.

Mammalian SQR is likely to have a structure very similar to that of the QFR enzymes. The flavoprotein and iron-sulfur protein subunits should be nearly identical in terms of subunit fold and prosthetic group location. The ambiguity in the structure lies in the membrane-bound subunits, especially the structure and location 
of the quinone binding sites. The $b$ heme should have an orientation similar to those of the hemes in the Wolinella succinogenes enzyme, although its precise location within the membrane-bound subunits is yet to be determined.

\section{Thermodynamics of Electron Transfer in SQR}

The reduction potentials of fumarate and ubiquinone are $10 \mathrm{mV}$ and $60 \mathrm{mV}$, respectively. Thus, the reduction of ubiquinone by succinate is moderately favorable $(\Delta \mathrm{G}=-100 \mathrm{meV})$ under standard conditions. In mammalian $\mathrm{SQR}$, the reported reduction potentials of FAD, S-1, S-2, S-3, and the $b$ heme are $-79,0$, $-260,60$, and $-185 \mathrm{mV}$, respectively $(5,92-94,146)$. Despite the fact that center $\mathrm{S}-2$ has a reduction potential much lower than those of fumarate and ubiquinone, the location of this cluster within the protein essentially requires it to be involved in mediating electron transfer from succinate to ubiquinone. Similarly, the $b$ heme of SQR has a very low potential; however, its location within the membrane subunits does not make it an obligatory electron carrier in this enzyme, and the role of this moiety in enzyme turnover is currently unclear.

In $E$. coli QFR, the reduction potentials of FAD, S-1, S-2, and S-3 are $-55,-20$, -320 , and $-70 \mathrm{mV}$, respectively $(3,21,111)$. The $\mathrm{S}-3$ center shows a substantially lower potential than that in SQR, in accord with S-3 being an electron donor for ubiquinone but an electron acceptor from menaquinol $\left(\mathrm{E}^{\circ \prime}=-74 \mathrm{mV}\right)$.

\section{Why Isn't SQR a Proton Pump?}

Of the complexes in the canonical mitochondrial respiratory chain, only SQR is not a proton pump. The most compelling reason why this is the case is that the electron transfer reactions catalyzed by SQR are not sufficiently exergonic to promote translocation. With an energy release of $50 \mathrm{meV}$ for each single electron transfer through the enzyme, an additional $150 \mathrm{mV}$ of driving force from the ([succinate][Q])/([fumarate][QH $\left.\mathrm{QH}_{2}\right]$ ) ratio would be required merely to make a proton transfer stoichiometry of $1 \mathrm{H}^{+} / 1 \mathrm{e}^{-}$thermoneutral, assuming perfect coupling of proton translocation to electron transfer. However, under normal physiological conditions, the $\left[\mathrm{QH}_{2}\right] /[\mathrm{Q}]$ ratio is high, suggesting that the electron transfer promoted by this enzyme is close to thermoneutral without any proton translocation.

The possibility of proton translocation occurring in SQR or QFR enzymes arose in part from the presence of prosthetic groups within the membrane-bound subunits. From the two known structures of quinol:fumarate oxidoreductases, it appears that for some enzymes there is a viable electron transfer pathway across the cytoplasmic or mitochondrial membrane. The presence of quinone/quinol binding sites on either side of the membrane, with one or two connecting heme groups, suggests a similarity to cytochrome $b$ of the $b c_{1}$ complex. This architecture appears to be superfluous if the sole purpose of SQR/QFR is to transfer electrons between fumarate and quinone, a feat that appears to require only the redox centers in the flavoprotein and the iron-sulfur protein along with quinone binding sites in the membrane. In an SQR enzyme in the bacterium Bacillus subtilis, the 
rate of electron transfer from succinate to menaquinone is enhanced in the presence of an electrochemical potential gradient (73), suggesting that the oxidation of succinate and the reduction of menaquinone occur on opposite sides of the cytoplasmic membrane. For QFR and SQR enzymes that are not affected by the membrane potential gradient, the presence of heme groups and distal quinone binding sites likely reflects the complexity of the quinone redox chemistry that occurs within the membrane-bound subunits. Further understanding of the role of these membrane-bound prosthetic groups, as well as the relationship between SQR and QFR enzymes, will come from the crystal structure determination of mitochondrial SQR or a related bacterial SQR enzyme.

\section{FINAL REMARKS}

Complexes I, III, and IV, the redox-linked proton pumps of the respiratory chain, are arguably the most difficult to understand in mechanistic terms. This is in part because the reaction intermediates critical for proton translocation are shortlived and difficult to study, and also because the magnitude of the conformational changes in the proteins necessary to promote proton pumping are expected to be subtle, transient, and complex in nature.

In general for a redox-linked proton pump, redox energy is converted into electrical work (proton translocation), potential energy, and heat. The potential energy, transiently stored in the protein, will be converted further into electrical work and heat. In describing the various electron transfer and proton transfer steps, the distinction between proton-coupled electron transfer and storage of redox energy in the protein followed by proton movement is not always clear. The first scenario implies that electron transfer is not kinetically or thermodynamically favored until a proton moves. The second implies that the electron transfer is thermodynamically and kinetically favorable, but that subsequent proton transfer will stabilize the system further. Even for the coupled electron/proton transfer, a distinction could be made between a concerted reaction versus a rapid, consecutive two-step process. Thus, for a given energy transduction step, the details of the energy transduction cannot be known without knowing the identity of any intermediates in the process.

For any redox-linked proton pump, the set of electron transfers, proton transfers, and conformational changes makes up the proton-pumping pathway. Deviations from this pathway constitute electron leaks and proton slips. In general, once the reaction cycle deviates from the pathway, the thermodynamics of electron transfer do not allow the enzyme to get back onto a fully productive proton-pumping path until the start of the next reaction cycle, in other words, until the futile cycle is aborted. The dedicated proton-pumping pathway begins with electron input into the enzyme, yet the bimolecular nature of the enzyme-substrate reaction makes this step difficult to access experimentally, as is particularly the case with Complexes I and IV. 
It is worth re-emphasizing that while the proton-pumping pathway is the only productive pathway with regard to generating the electrochemical potential gradient, it is not the only means of converting chemical substrates to products. For each electron transfer through a proton-pumping enzyme, the transfer may be coupled to proton translocation, or a more favorable electron transfer pathway may be taken that does not involve proton pumping. Likewise, the electrochemical potential gradient will force protons toward the matrix side of the membrane unless the redox-linked conformational changes in the protein provide the unidirectional proton pumping. In light of these points, a mechanistic understanding of a proton pump requires not merely knowing what happens at every step in the proton pumping cycle, but also why thermodynamically favored electron leaks and proton slips do not occur instead.

The unresolved questions with regard to the proton translocation mechanisms of the respiratory enzymes are essentially the same for all of the enzymes. A complete mechanistic description of these enzymes requires knowing the molecular structure of the protein, the nature of the substrate-enzyme interactions and substrate transformations, electron transfer pathways in the enzyme, kinetics and thermodynamics of electron transfer, conformational changes associated with electron transfer, the specific protonation/deprotonation reactions of amino acid residues and small-molecule proton carriers, the coupling of electron transfer and proton transfer, and the means by which unidirectional flow of protons is assured. To a significant extent, these factors constitute a heirarchy of understanding in that the subtle details of proton pumping cannot be understood without first understanding the fundamental structure and enzymology of the proteins. The solution of the crystal structures of the mitochondrial respiratory enzymes and their bacterial counterparts has been a crucial contribution to our current views of proton translocation. Molecular structures of Complex I and of reaction intermediates of all of the proton pumps in the respiratory chain will undoubtedly be required before a full understanding of the workings of these enzymes is obtained.

\section{ACKNOWLEDGMENTS}

We would like to thank Tina Iverson for assistance in the preparation of several figures presented in this work and for many helpful discussions.

\section{Visit the Annual Reviews home page at www.AnnualReviews.org}

\section{LITERATURE CITED}

1. Abrahams JP, Buchanan SK, Van Raaij MJ, Fearnley IM, Leslie AGW, Walker JE. 1996. The structure of bovine $\mathrm{F}_{1}$-ATPase complexed with the peptide antibiotic efrapeptin. Proc. Natl. Acad. Sci. USA 93: 9420-24

2. Abrahams JP, Leslie AGW, Lutter R, Walker JE. 1994. Structure at $2.8 \AA$ resolution of 
$\mathrm{F}_{1}$-ATPase from bovine heart mitochondria. Nature 370:621-28

3. Ackrell BAC, Cochran B, Cecchini G. 1989. Interactions of oxaloacetate with Escherichia coli fumarate reductase. Arch. Biochem. Biophys. 268:26-34

4. Ackrell BAC, Johnson MK, Gunsalus RP, Cecchini G. 1992. Structure and function of succinate dehydrogenase and fumarate reductase. In Chemistry and Biochemistry of Flavoenzymes, ed. $\mathrm{F}$ Müller, 3:229-97. Boca Raton, FL: CRC Press

5. Ackrell BAC, Kearney EB, Edmondson D. 1975. Mechanism of the reductive activation of succinate dehydrogenase. J. Biol. Chem. 250:7114-19

6. Albracht SPJ, Bakker PTA. 1986. Evidence for two independent pathways of electron transfer in mitochondrial NADH:Q oxidoreductase. II. Kinetics of reoxidation of the reduced enzyme. Biochim. Biophys. Acta 850:423-28

7. Ambler RP. 1991. Sequence variability in bacterial cytochromes $c$. Biochim. Biophys. Acta 1058:42-47

8. Archer CD, Wang X, Elliott T. 1993. Mutants defective in the energy-conserving $\mathrm{NADH}$ dehydrogenase of Salmonella typhimurium identified by a decrease in energy-dependent proteolysis after carbon starvation. Proc. Natl. Acad. Sci. USA 90: 9877-81

9. Bakker PTA, Albracht SPJ. 1986. Evidence for two independent pathways of electron transfer in mitochondrial NADH:Q oxidoreductase. I. Pre-steady-state kinetics with NADPH. Biochim. Biophys. Acta 850:413-22

10. Behr J, Michel H, Mäntele W, Hellwig P. 2000. Functional properties of the heme propionates in cytochrome $c$ oxidase from Paracoccus denitrificans. Evidence from FTIR difference spectroscopy and sitedirected mutagenesis. Biochemistry 39: 1356-63

11. Bianchet MA, Hullihen J, Pedersen PL,
Amzel LM. 1998. The 2.8- $\AA$ structure of rat liver $\mathrm{F}_{1}$-ATPase: configuration of a critical intermediate in ATP synthesis/hydrolysis. Proc. Natl. Acad. Sci. USA 95: 11065-70

12. Bickar D, Bonaventura J, Bonaventura C. 1982. Cytochrome $c$ oxidase binding of hydrogen peroxide. Biochemistry 21:266166

13. Blackburn NJ, de Vries S, Barr ME, Houser RP, Tolman WB, et al. 1997. X-ray absorption studies on the mixed-valence and fully reduced forms of the soluble $\mathrm{Cu}_{\mathrm{A}}$ domains of cytochrome $c$ oxidase. J. Am. Chem. Soc. 119:6135-43

14. Blair DF, Witt SN, Chan SI. 1985. Mechanism of cytochrome $c$ oxidase-catalyzed dioxygen reduction at low temperatures. Evidence for two intermediates at the threeelectron level and entropic promotion of the bond-breaking step. J. Am. Chem. Soc. 107:7389-99

15. Boyer PD. 1993. The binding change mechanism for ATP synthase-some probabilities and possibilities. Biochim. Biophys. Acta 1140:215-50

16. Boyer PD. 1997. The ATP synthase-a splendid molecular machine. Annu. Rev. Biochem. 66:717-49

17. Brandt U. 1997. Proton-translocation by membrane-bound NADH:ubiquinone-oxidoreductase (complex I) through redoxgated ligand conduction. Biochim. Biophys. Acta 1318:79-91

18. Brandt U, Trumpower B. 1994. The protonmotive $Q$ cycle in mitochondria and bacteria. Crit. Rev. Biochem. Mol. Biol. 29:16597

19. Brandt U, von Jagow G. 1991. Analysis of inhibitor binding to the mitochondrial cytochrome $c$ reductase by fluorescence quench titration. Evidence for a 'catalytic switch' at the $\mathrm{Q}_{\mathrm{o}}$ center. Eur. J. Biochem. 195:163-70

20. Buchanan SK, Walker JE. 1996. Largescale chromatographic purification of $\mathrm{F}_{1} \mathrm{~F}_{0}$-ATPase and complex I from bovine 
heart mitochondria. Biochem. J. 318:34349

21. Cammack R, Patil DS, Condon C, Owen P, Cole ST, Weiner JH. 1984. ESR spectroscopic studies of succinate dehydrogenase and fumarate reductase from Esherichia coli. In Flavins and Flavoproteins, ed. RC Bray, PC Engel, SG Mayhew, pp. 551-54. Berlin: Walter de Gruyter

22. Capitanio N, Vygodina TV, Capitanio G, Konstantinov AA, Nicholls P, Papa S. 1997. Redox-linked protolytic reactions in soluble cytochrome- $c$ oxidase from beefheart mitochondria: redox Bohr effects. Biochim. Biophys. Acta 1318:255-65

23. Chance B, Saronio C, Leigh JS Jr. 1975. Functional intermediates in reaction of cytochrome oxidase with oxygen. Proc. Natl. Acad. Sci. USA 72:1635-40

24. Clore GM, Andréasson LE, Karlsson B, Aasa R, Malmström BG. 1980. Characterization of the intermediates in the reaction of mixed-valence-state soluble cytochrome oxidase with oxygen at low temperatures by optical and electron-paramagneticresonance spectroscopy. Biochem. J. 185: 155-67

25. Clore GM, Andréasson LE, Karlsson B, Aasa R, Malmström BG. 1980. Characterization of the low-temperature intermediates of the reaction of fully reduced soluble cytochrome oxidase with oxygen by electron-paramagnetic-resonance and optical spectroscopy. Biochem. J. 185:139-54

26. Collinson IR, Runswick MJ, Buchanan SK, Fearnley IM, Skehel JM, et al. 1994. Fo membrane domain of ATP synthase from bovine heart mitochondria: purification, subunit composition, and reconstitution with $\mathrm{F}_{1}$-ATPase. Biochemistry 33:7971-78

27. Collinson IR, Skehel JM, Fearnley IM, Runswick MJ, Walker JE. 1996. The $\mathrm{F}_{1} \mathrm{~F}_{0^{-}}$ ATPase complex from bovine heart mitochondria: the molar ratio of the subunits in the stalk region linking the $\mathrm{F}_{1}$ and $\mathrm{F}_{0}$ domains. Biochemistry 35:12640-46

28. Crofts AR, Barquera B, Gennis RB, Kuras
R, Guergova-Kuras M, Berry EA. 1999. Mechanism of ubiquinol oxidation by the $b c_{1}$ complex: different domains of the quinol binding pocket and their role in the mechanism and binding of inhibitors. Biochemistry 38:15807-26

29. Crofts AR, Guergova-Kuras M, Huang L, Kuras R, Zhang Z, Berry EA. 1999. Mechanism of ubiquinol oxidation by the $b c_{1}$ complex: role of the iron sulfur protein and its mobility. Biochemistry 38:15791-806

30. Davenport JW, McCarty RE. 1984. An analysis of proton fluxes coupled to electron transport and ATP synthesis in chloroplast thylakoids. Biochim. Biophys. Acta 766:363-74

31. Degli Esposti M, Ngo A, McMullen GL, Ghelli A, Sparla F, et al. 1996. The specificity of mitochondrial complex I for ubiquinones. Biochem. J. 313:327-34

32. de Vries S, Albracht SPJ, Berden JA, Slater EC. 1982. The pathway of electrons through $\mathrm{QH}_{2}$ :cytochrome $c$ oxidoreductase studied by pre-steady-state kinetics. Biochim. Biophys. Acta 681:41-53

33. Dupuis A, Chevallet M, Darrouzet E, Duborjal H, Lunardi J, Issartel JP. 1998. The complex I from Rhodobacter capsulatus. Biochim. Biophys. Acta 1364:147-65

34. Dutton PL, Moser CC, Sled VD, Daldal F, Ohnishi T. 1998. A reductant-induced oxidation mechanism for complex I. Biochim. Biophys. Acta 1364:245-57

35. Earley FG, Patel SD, Ragan I, Attardi G. 1987. Photolabelling of a mitochondrially encoded subunit of NADH dehydrogenase with $\left[{ }^{3} \mathrm{H}\right]$ dihydrorotenone. FEBS Lett. 219:108-12

36. Esnouf RM. 1997. An extensively modified version of Molscript that includes greatly enhanced coloring capabilities. $J$. Mol. Graph. Model. 15:132-34

37. Fearnley IM, Walker JE. 1992. Conservation of sequences of subunits of mitochondrial complex I and their relationships with other proteins. Biochim. Biophys. Acta 1140:105-34 
38. Fetter JR, Qian J, Shapleigh J, Thomas JW, García-Horsman A, et al. 1995. Possible proton relay pathways in cytochrome $c$ oxidase. Proc. Natl. Acad. Sci. USA 92:16048

39. Fillingame RH. 1990. Molecular mechanics of ATP synthesis by $\mathrm{F}_{1} \mathrm{~F}_{0}$-type $\mathrm{H}^{+}$transporting ATP synthases. Bacteria 12: 345-91

40. Finel M, Majander AS, Tyynelä J, De Jong AMP, Albracht SPJ, Wikström M. 1994. Isolation and characterisation of subcomplexes of the mitochondrial NADH:ubiquinone oxidoreductase (complex I). Eur. J. Biochem. 226:237-42

41. Finel M, Skehel JM, Albracht SPJ, Fearnley IM, Walker JE. 1992. Resolution of NADH:ubiquinone oxidoreductase from bovine heart mitochondria into two subcomplexes, one of which contains the redox centers of the enzyme. Biochemistry 31:11425-34

42. Foster DL, Fillingame RH. 1982. Stoichiometry of subunits in the $\mathrm{H}^{+}$-ATPase complex of Escherichia coli. J. Biol. Chem. 257:2009-15

43. Friedrich T, Hofhaus G, Ise W, Nehls U, Schmitz B, Weiss H. 1989. A small isoform of NADH:ubiquinone oxidoreductase (complex I) without mitochondrially encoded subunits is made in chloramphenicol-treated Neurospora crassa. Eur. J. Biochem. 180:173-80

44. Friedrich T, van Heek P, Leif H, Ohnishi T, Forche E, et al. 1994. Two binding sites of inhibitors in NADH:ubiquinone oxidoreductase (complex I). Relationship of one site with the ubiquinone-binding site of bacterial glucose:ubiquinone oxidoreductase. Eur. J. Biochem. 219:69198

45. Galante YM, Hatefi Y. 1979. Purification and molecular and enzymic properties of mitochondrial NADH dehydrogenase. Arch. Biochem. Biophys. 192:559-68

46. García-Horsman JA, Barquera B, Rumbley J, Ma J, Gennis RB. 1994. The superfamily of heme-copper respiratory oxidases. $J$. Bacteriol. 176:5587-600

47. Girvin ME, Rastogi VK, Abildgaard F, Markley JL, Fillingame RH. 1998. Solution structure of the transmembrane $\mathrm{H}^{+}$transporting subunit $\mathrm{c}$ of the $\mathrm{F}_{1} \mathrm{~F}_{0}$ ATP synthase. Biochemistry 37:8817-24

48. Guénebaut V, Schlitt A, Weiss H, Leonard K, Friedrich T. 1998. Consistent structure between bacterial and mitochondrial NADH:ubiquinone oxidoreductase (complex I). J. Mol. Biol. 276:105-12

49. Guénebaut V, Vincentelli R, Mills D, Weiss H, Leonard KR. 1997. Three-dimensional structure of NADH-dehydrogenase from Neurospora crassa by electron microscopy and conical tilt reconstruction. J. Mol. Biol. 265:409-18

50. Hägerhäll C. 1997. Succinate:quinone oxidoreductases. Variations on a conserved theme. Biochim. Biophys. Acta 1320:10741

51. Han SW, Ching YC, Rousseau DL. 1990. Ferryl and hydroxy intermediates in the reaction of oxygen with reduced cytochrome $c$ oxidase. Nature 348:89-90

52. Han SW, Ching YC, Rousseau DL. 1990. Primary intermediate in the reaction of mixed-valence cytochrome $c$ oxidase with oxygen. Biochemistry 29:1380-84

53. Han SW, Ching YC, Rousseau DL. 1990. Primary intermediate in the reaction of oxygen with fully reduced cytochrome $c$ oxidase. Proc. Natl. Acad. Sci. USA 87: 2491-95

54. Hansen KC, Schultz BE, Wang G, Chan SI. 2000. Reaction of Escherichia coli cytochrome $b_{3}$ and mitochondrial cytochrome $b c_{1}$ with a photoreleasable decylubiquinol. Biochim. Biophys. Acta 1456: 121-37

55. Harrenga A, Michel H. 1999. The cytochrome c oxidase from Paracoccus denitrificans does not change the metal center ligation upon reduction. J. Biol. Chem. 274:33296-99

56. Hendler RW, Pardhasaradhi K, Reynafarje 
B, Ludwig B. 1991. Comparison of energytransducing capabilities of the two- and three-subunit cytochromes $a a_{3}$ from Paracoccus denitrificans and the 13-subunit beef heart enzyme. Biophys. J. 60:415-23

57. Hofhaus G, Weiss H, Leonard K. 1991. Electron microscopic analysis of the peripheral and membrane parts of mitochondrial NADH dehydrogenase (complex I). $J$. Mol. Biol. 221:1027-43

58. Hosler JP, Ferguson-Miller S, Calhoun MW, Thomas JW, Hill J, et al. 1993. Insight into the active-site structure and function of cytochrome oxidase by analysis of site-directed mutants of bacterial cytochrome $a a_{3}$ and cytochrome bo. J. Bioenerg. Biomembr. 25:121-36

59. Hosler JP, Shapleigh JP, Mitchell DM, Kim Y, Pressler MA, et al. 1996. Polar residues in helix VIII of subunit I of cytochrome $c$ oxidase influence the activity and the structure of the active site. Biochemistry 35:10776-83

60. Howitt SM, Gibson F, Cox GB. 1988. The proton pore of the $\mathrm{F}_{0} \mathrm{~F}_{1}$-ATPase of Escherichia coli: Ser-206 is not required for proton translocation. Biochim. Biophys. Acta 936:74-80

61. Ingledew WJ, Ohnishi T. 1980. An analysis of some thermodynamic properties of iron-sulphur centres in site I of mitochondria. Biochem. J. 186:111-17

62. Iverson TM, Luna-Chavez C, Cecchini G, Rees DC. 1999. Structure of the Escherichia coli fumarate reductase respiratory complex. Science 284:1961-66

63. Iwata S, Lee JW, Okada K, Lee JK, Iwata M, et al. 1998. Complete structure of the 11-subunit bovine mitochondrial cytochrome $b c_{1}$ complex. Science 281:64-71

64. Iwata S, Ostermeier C, Ludwig B, Michel H. 1995. Structure at $2.8 \AA$ resolution of cytochrome $c$ oxidase from Paracoccus denitrificans. Nature 376:660-69

65. Karlsson B, Aasa R, Vänngård T, Mallmström BG. 1981. An EPR-detectable intermediate in the cytochrome oxidase- dioxygen reaction. FEBS Lett. 131:186-88

66. Kato-Yamada Y, Noji H, Yasuda R, Kinosita K Jr, Yoshida M. 1998. Direct observation of the rotation of $\varepsilon$ subunit in $\mathrm{F}_{1^{-}}$ ATPase. J. Biol. Chem. 273:19375-77

67. Kim H, Xia D, Yu CA, Xia JZ, Kachurin AM, et al. 1998. Inhibitor binding changes domain mobility in the iron-sulfur protein of the mitochondrial $b c_{1}$ complex from bovine heart. Proc. Natl. Acad. Sci. USA 95:8026-33

68. Kraulis PJ. 1991. MOLSCRIPT: a program to produce both detailed and schematic plots of protein structures. J. Appl. Crystallogr. 24:946-50

69. Lancaster CR, Kröger A, Auer M, Michel H. 1999. Structure of fumarate reductase from Wolinella succinogenes at $2.2 \AA$ resolution. Nature 402:377-85

70. Lee H-M, Das TK, Rousseau DL, Mills D, Ferguson-Miller S, Gennis RB. 2000. Mutations in the putative $\mathrm{H}$-channel in the cytochrome $c$ oxidase from Rhodobacter sphaeroides show that this channel is not important for proton conduction but reveal modulation of the properties of heme $a$. Biochemistry 39:2989-96

71. Lehninger AL. 1984. Proton translocation coupled to mitochondrial electron transport. Biochem. Soc. Trans. 12:386-88

72. Leif H, Sled' VD, Ohnishi T, Weiss H, Friedrich T. 1995. Isolation and characterization of the proton-translocating NADH:ubiquinone oxidoreductase from Escherichia coli. Eur. J. Biochem. 230: 538-48

73. Lemma E, Unden G, Kröger A. 1990. Menaquinone is an obligatory component of the chain catalyzing succinate respiration in Bacillus subtilis. Arch. Microbiol. 155:62-67

74. Malatesta F, Antonini G, Sarti P, Brunori M. 1995. Structure and function of a molecular machine: cytochrome $c$ oxidase. Biophys. Chem. 54:1-33

75. Maloney PC. 1987. Coupling to an energized membrane: role of ion-motive 
gradients in the transduction of metabolic energy. In Escherichia coli and Salmonella typhimurium: Cellular and Molecular Biology, ed. FC Neidhardt, 1:222-43. Washington, DC: Am. Soc. Microbiol

76. Merritt EA, Murphy MEP. 1994. Raster3D version 2.0. A program for photorealistic molecular graphics. Acta Crystallogr. D 50:869-73

77. Michel H, Behr J, Harrenga A, Kannt A. 1998. Cytochrome $c$ oxidase: structure and spectroscopy. Annu. Rev. Biophys. Biomol. Struct. 27:329-56

78. Miki T, Orii Y. 1986. Cytochrome $c$ peroxidase activity of bovine heart cytochrome oxidase incorporated in liposomes and generation of membrane potential. J. Biochem. 100:735-45

79. Miki T, Orii Y. 1986. Proton translocation by cytochrome oxidase vesicles catalyzing the peroxidatic oxidation of ferrocytochrome c. J. Biol. Chem. 261:3915-18

80. Mitchell DM, Aasa R, Ädelroth P, Brzezinski P, Gennis RB, Malmström BG. 1995. EPR studies of wild-type and several mutants of cytochrome $c$ oxidase from Rhodobacter sphaeroides: Glu286 is not a bridging ligand in the cytochrome $a_{3}-\mathrm{Cu}_{\mathrm{B}}$ center. FEBS Lett. 374:371-74

81. Mitchell P. 1976. Possible molecular mechanisms of the protonmotive function of cytochrome systems. J. Theor. Biol. 62:32767

82. Mitchell R, Mitchell P, Rich PR. 1992. Protonation states of the catalytic intermediates of cytochrome $c$ oxidase. Biochim. Biophys. Acta 1101:188-91

83. Mitchell R, Rich PR. 1994. Proton uptake by cytochrome $c$ oxidase on reduction and on ligand binding. Biochim. Biophys. Acta 1186:19-26

84. Murphy ME, Lindley PF, Adman ET. 1997. Structural comparison of cupredoxin domains: domain recycling to construct proteins with novel functions. Protein Sci. 6:761-70

85. Musser SM, Chan SI. 1995. Understanding the cytochrome $c$ oxidase proton pump: thermodynamics of redox linkage. Biophys. J. 68:2543-55

86. Musser SM, Stowell MHB, Chan SI. 1995. Cytochrome $c$ oxidase: chemistry of a molecular machine. Adv. Enzymol. Relat. Areas Mol. Biol. 71:79-208

87. Noji H, Yasuda R, Yoshida M, Kinosita K Jr. 1997. Direct observation of the rotation of $\mathrm{F}_{1}$-ATPase. Nature 386:299-302

88. Ogura T, Takahashi S, Hirota S, ShinzawaItoh K, Yoshikawa S, et al. 1993. Timeresolved resonance Raman elucidation of the pathway for dioxygen reduction by cytochrome $c$ oxidase. J. Am. Chem. Soc. 115:8527-36

89. Ogura T, Takahashi S, Shinzawa-Itoh K, Yoshikawa S, Kitagawa T. 1990. Observation of the $\mathrm{Fe}^{4+}=\mathrm{O}$ stretching Raman band for cytochrome oxidase compound $\mathrm{B}$ at ambient temperature. J. Biol. Chem. 265:14721-23

90. Ogura T, Takahashi S, Shinzawa-Itoh K, Yoshikawa S, Kitagawa T. 1990. Observation of the $\mathrm{Fe}^{\mathrm{II}}-\mathrm{O}_{2}$ stretching Raman band for cytochrome oxidase compound $\mathrm{A}$ at ambient temperature. J. Am. Chem. Soc. 112:5630-31

91. Ohnishi T. 1975. Thermodynamic and EPR characterization of iron-sulfur centers in the NADH-ubiquinone segment of the mitochondrial respiratory chain in pigeon heart. Biochim. Biophys. Acta 387:47590

92. Ohnishi T, King TE, Salerno JC, Blum H, Bowyer JR, Maida T. 1981. Thermodynamic and electron paramagnetic resonance characterization of flavin in succinate dehydrogenase. J. Biol. Chem. 256: 5577-82

93. Ohnishi T, Salerno JC. 1976. Thermodynamic and EPR characteristics of two ferredoxin-type iron-sulfur centers in the succinate-ubiquinone reductase segment of the respiratory chain. J. Biol. Chem. 251:2094-104

94. Ohnishi T, Winter DB, Lim J, King 
TE. 1974. EPR studies on a HiPIP type iron-sulfur center in the succinate dehydrogenase segment of the respiratory chain. Biochim. Biophys. Res. Commun. 61:1017-25

95. Orme-Johnson NR, Hansen RE, Beinert H. 1974. Electron paramagnetic resonance-detectable electron acceptors in beef heart mitochondria. Ubihydroquinone-cytochrome $c$ reductase segment of the electron transfer system and complex mitochondrial fragments. J. Biol. Chem. 249:1928-39

96. Orriss GL, Leslie AGW, Braig K, Walker JE. 1998. Bovine $\mathrm{F}_{1}$-ATPase covalently inhibited with 4-chloro-7nitrobenzofurazan: the structure provides further support for a rotary catalytic mechanism. Structure 6:831-37

97. Ostermeier C, Harrenga A, Ermler U, Michel H. 1997. Structure at $2.7 \AA$ Å resolution of the Paracoccus denitrificans twosubunit cytochrome $c$ oxidase complexed with an antibody $\mathrm{F}_{\mathrm{V}}$ fragment. Proc. Natl. Acad. Sci. USA 94:10547-53

98. Pfitzner U, Odenwald A, Ostermann T, Weingard L, Ludwig B, Richter OMH. 1998. Cytochrome $c$ oxidase (heme $a a_{3}$ ) from Paracoccus denitrificans: analysis of mutations in putative proton channels of subunit I. J. Bioenerg. Biomembr. 30:89-97

99. Prochaska LJ, Fink PS. 1987. On the role of subunit III in proton translocation in cytochrome $c$ oxidase. J. Bioenerg. Biomembr. 19:143-66

100. Proshlyakov DA, Ogura T, ShinzawaItoh K, Yoshikawa S, Appelman EH, Kitagawa T. 1994. Selective resonance Raman observation of the " $607 \mathrm{~nm}$ " form generated in the reaction of oxidized cytochrome $c$ oxidase with hydrogen peroxide. J. Biol. Chem. 269:29385-88

101. Ragan CI. 1987. Structure of NADHubiquinone reductase (complex I). Curr. Top. Bioenerget. 15:1-36

102. Ragan CI, Galante YM, Hatefi Y. 1982.
Purification of three iron-sulfur proteins from the iron-protein fragment of mitochondrial NADH-ubiquinone oxidoreductase. Biochemistry 21:2518-24

103. Ragan CI, Galante YM, Hatefi Y, Ohnishi T. 1982. Resolution of mitochondrial $\mathrm{NADH}$ dehydrogenase and isolation of two iron-sulfur proteins. Biochemistry 21:590-94

104. Ralle M, Verkhovskaya ML, Morgan JE, Verkhovsky MI, Wikström M, Blackburn NJ. 1999. Coordination of $\mathrm{Cu}_{\mathrm{B}}$ in reduced and CO-liganded states of cytochrome $\mathrm{bo}_{3}$ from Escherichia coli. Is chloride ion a cofactor? Biochemistry 38:7185-94

105. Rich PR. 1984. Electron and proton transfers through quinones and cytochrome bc complexes. Biochim. Biophys. Acta 768:53-79

106. Ruzicka FJ, Beinert H, Schepler KL, Dunham WR, Sands RH. 1975. Interaction of ubisemiquinone with a paramagnetic component in heart tissue. Proc. Natl. Acad. Sci. USA 72:2886-90

107. Sambongi Y, Iko Y, Tanabe M, Omote H, Iwamoto-Kihara A, et al. 1999. Mechanical rotation of the $\mathrm{c}$ subunit oligomer in ATP synthase $\left(\mathrm{F}_{0} \mathrm{~F}_{1}\right)$ : direct observation. Science 286:1722-24

108. Sebald W, Machleidt W, Wachter E. 1980. $N, N^{\prime}$-dicyclohexylcarbodiimide binds specifically to a single glutamyl residue of the proteolipid subunit of the mitochondrial adenosinetriphosphatases from Neurospora crassa and Saccharomyces cerevisiae. Proc. Natl. Acad. Sci. USA 77:785-89

109. Senior AE. 1990. The proton-translocating ATPase of Escherichia coli. Annu. Rev. Biophys. Biophys. Chem. 19:7-41

110. Shirakihara Y, Leslie AGW, Abrahams JP, Walker JE, Ueda T, et al. 1997. The crystal structure of the nucleotide-free $\alpha_{3} \beta_{3}$ subcomplex of $F_{1}$-ATPase from the thermophilic Bacillus PS3 is a symmetric trimer. Structure 5:825-36

111. Simpkin D, Ingledew WJ. 1985. The 
membrane-bound fumarate reductase of Escherichia coli: an electron-paramagnetic-resonance study. Biochem. Soc. Trans. 13:603-7

112. Singer TP, Ramsay RR. 1994. The reaction sites of rotenone and ubiquinone with mitochondrial NADH dehydrogenase. Biochim. Biophys. Acta 1187:198202

113. Sled' VD, Friedrich T, Leif H, Weiss H, Meinhardt SW, et al. 1993. Bacterial NADH-quinone oxidoreductases: ironsulfur clusters and related problems. $J$. Bioenerg. Biomembr. 25:347-56

114. Sled' VD, Rudnitzky NI, Hatefi Y, Ohnishi T. 1994. Thermodynamic analysis of flavin in mitochondrial NADH: ubiquinone oxidoreductase (complex I). Biochemistry 33:10069-75

115. Snyder C, Trumpower BL. 1998. Mechanism of ubiquinol oxidation by the cytochrome $b c_{1}$ complex: pre-steady-state kinetics of cytochrome $b c_{1}$ complexes containing site-directed mutants of the Rieske iron-sulfur protein. Biochim. Biophys. Acta 1365:125-34

116. Stock D, Leslie AGW, Walker JE. 1999. Molecular architecture of the rotary motor in ATP synthase. Science 286:1700-5

117. Strotmann H, Lohse D. 1988. Determination of the $\mathrm{H}^{+} /$ATP ratio of the $\mathrm{H}^{+}$ transport-coupled reversible chloroplast ATPase reaction by equilibrium studies. FEBS Lett. 229:308-12

118. Trumpower BL. 1990. Cytochrome $b c_{1}$ complexes of microorganisms. Microbiol. Rev. 54:101-29

119. Trumpower BL, Gennis RB. 1994. Energy transduction by cytochrome complexes in mitochondrial and bacterial respiration: the enzymology of coupling electron transfer reactions to transmembrane proton translocation. Annu. Rev. Biochem. 63:675-716

120. Tsukihara T, Aoyama H, Yamashita E, Tomizaki T, Yamaguchi H, et al. 1995. Structures of metal sites of oxidized bovine heart cytochrome $c$ oxidase at 2.8 Å. Science 269:1069-74

121. Tsukihara T, Aoyama H, Yamashita E, Tomizaki T, Yamaguchi H, et al. 1996. The whole structure of the 13-subunit oxidized cytochrome $c$ oxidase at $2.8 \AA$. Science 272:1136-44

122. van Belzen R, Kotlyar AB, Moon N, Dunham WR, Albracht SPJ. 1997. The ironsulfur clusters 2 and ubisemiquinone radicals of NADH:ubiquinone oxidoreductase are involved in energy coupling in submitochondrial particles. Biochemistry 36:886-93

123. van Raaij MJ, Abrahams JP, Leslie AGW, Walker JE. 1996. The structure of bovine $\mathrm{F}_{1}$-ATPase complexed with the antibiotic inhibitor aurovertin B. Proc. Natl. Acad. Sci. USA 93:6913-17

124. van Walraven HS, Strotmann H, Schwarz O, Rumberg B. 1996. The $\mathrm{H}^{+} /$ATP coupling ratio of the ATP synthase from thiol-modulated chloroplasts and two cyanobacterial strains is four. FEBS Lett. 379:309-13

125. Varotsis C, Babcock GT. 1990. Appearance of the $v\left(\mathrm{Fe}^{\mathrm{IV}}=\mathrm{O}\right)$ vibration from a ferryl-oxo intermediate in the cytochrome oxidase/dioxygen reaction. Biochemistry 29:7357-62

126. Varotsis C, Woodruff WH, Babcock GT. 1989. Time-resolved Raman detection of $v(\mathrm{Fe}-\mathrm{O})$ in an early intermediate in the reduction of $\mathrm{O}_{2}$ by cytochrome oxidase. $J$. Am. Chem. Soc. 111:6439-40. Erratum. 1990. J. Am. Chem. Soc. 112:1297

127. Varotsis C, Woodruff WH, Babcock GT. 1990. Direct detection of a dioxygen adduct of cytochrome $a_{3}$ in the mixed valence cytochrome oxidase/dioxygen reaction. J. Biol. Chem. 265:11131-36

128. Vinogradov AD, Sled' VD, Burbaev DS, Grivennikova VG, Moroz IA, Ohnishi T. 1995. Energy-dependent complex I-associated ubisemiquinones in submitochondrial particles. FEBS Lett. 370:83-87

129. Vygodina TV, Capitanio N, Papa S, 
Konstantinov AA. 1997. Proton pumping by cytochrome $c$ oxidase is coupled to peroxidase half of its catalytic cycle. FEBS Lett. 412:405-9

130. Walker JE. 1992. The NADH:ubiquinone oxidoreductase (complex I) of respiratory chains. Q. Rev. Biophys. 25:253-324

131. Walker JE, Skehel JM, Buchanan SK. 1995. Structural analysis of NADH:ubiquinone oxidoreductase from bovine heart mitochondria. Methods Enzymol. 260: 14-34

132. Wang DC, Meinhardt SW, Sackmann U, Weiss H, Ohnishi T. 1991. The iron-sulfur clusters in the two related forms of mitochondrial NADH:ubiquinone oxidoreductase made by Neurospora crassa. Eur. J. Biochem. 197:257-64

133. Weidner U, Geier S, Ptock A, Friedrich T, Leif H, Weiss H. 1993. The gene locus of the proton-translocating $\mathrm{NADH}$ : ubiquinone oxidoreductase in Escherichia coli. Organization of the 14 genes and relationship between the derived proteins and subunits of mitochondrial complex I. J. Mol. Biol. 233:109-22

134. Wikström M. 1981. Energy-dependent reversal of the cytochrome oxidase reaction. Proc. Natl. Acad. Sci. USA 78:4051-54

135. Wikström M. 1989. Identification of the electron transfers in cytochrome oxidase that are coupled to proton-pumping. Nature 338:776-78

136. Wikström M, Morgan JE. 1992. The dioxygen cycle. Spectral, kinetic, and thermodynamic characteristics of ferryl and peroxy intermediates observed by reversal of the cytochrome oxidase reaction. J. Biol. Chem. 267:10266-73

137. Williams PA, Blackburn NJ, Sanders D, Bellamy H, Stura EA, et al. 1999. The $\mathrm{Cu}_{\mathrm{A}}$ domain of Thermus thermophilus $b a_{3}$-type cytochrome $c$ oxidase at $1.6 \AA$ resolution. Nat. Struct. Biol. 6:509-16

138. Witt H, Zickermann V, Ludwig B. 1995.
Site-directed mutagenesis of cytochrome $c$ oxidase reveals two acidic residues involved in the binding of cytochrome $c$. Biochim. Biophys. Acta 1230:74-76

139. Witt SN, Blair DF, Chan SI. 1986. Chemical and spectroscopic evidence for the formation of a ferryl $\mathrm{Fe}_{\mathrm{a} 3}$ intermediate during turnover of cytochrome $c$ oxidase. $J$. Biol. Chem. 261:8104-7.

140. Witt SN, Chan SI. 1987. Evidence for a ferryl $\mathrm{Fe}_{\mathrm{a} 3}$ in oxygenated cytochrome $c$ oxidase. J. Biol. Chem. 262:1446-48

141. Wriggleswortg JM. 1984. Formation and reduction of a 'peroxy' intermediate of cytochrome $c$ oxidase by hydrogen peroxide. Biochem. J. 217:715-19

142. Xia D, Yu CA, Kim H, Xia JZ, Kachurin AM et al. 1997. Crystal structure of the cytochrome $b c_{1}$ complex from bovine heart mitochondria. Science 277:60-66

143. Yagi T. 1993. The bacterial energytransducing NADH-quinone oxidoreductase. Biochim Biophy. Acta 1141:1-17

144. Yano T, Chu SS, Sled' VD, Ohnishi T, Yagi T. 1997. The proton-translocating $\mathrm{NADH}$-quinone oxidoreductase $\mathrm{NDH}-$ 1) of thermophilic bacterium Thermus thermophilus HB-8. Complete DNA sequence of the gene cluster and thermostable properties of the expressed NQO2 subunit. J. Biol. Chem. 272:420111

145. Yoshikawa S, Shinzawa-Itoh K, Nakashima R, Yaono R, Yamashita E et al. 1998. REdox-coupled crystal structural changes in bovine heart cytochrome c oxidase. Science 280:1723-29

146. Yu L, Xu J-X, Haley PE, Yu C-A. 1987. Properties of bovine heart mitochondrial cytochrome $b_{560}$. J. Biol. Chem. 262: 1137-43

147. Zhang ZL, Huang LS, Shulmeister VM, Chi YI, Kim KK, et al. 1998. Electrons transfer by domain movement in cytochrome $b c_{1}$. Nature 392:677-84 


\section{Complex I Complex II Complex III Complex IV Complex V}

cytochrome $c$

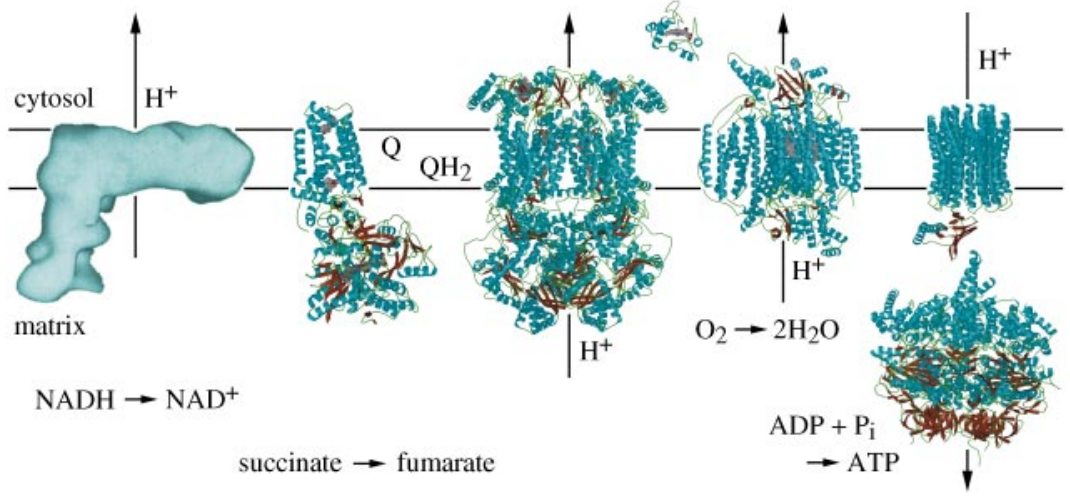

Figure 1 The mitochondrial respiratory chain. Structures are of mitochondrial enzymes or bacterial analogs. Protein Data Bank (PDB) accession codes 1FUM, 1BGY, 1CXA, 1OCC, 1QO1. Crystal structure plots in this figure and in Figures 2, 4, 5, 7, and 11 were generated and rendered with the programs MOLSCRIPT (68), BOBSCRIPT (36), and Raster3D (76). The Complex I structure was reproduced from reference 49 with the permission of Academic Press. 


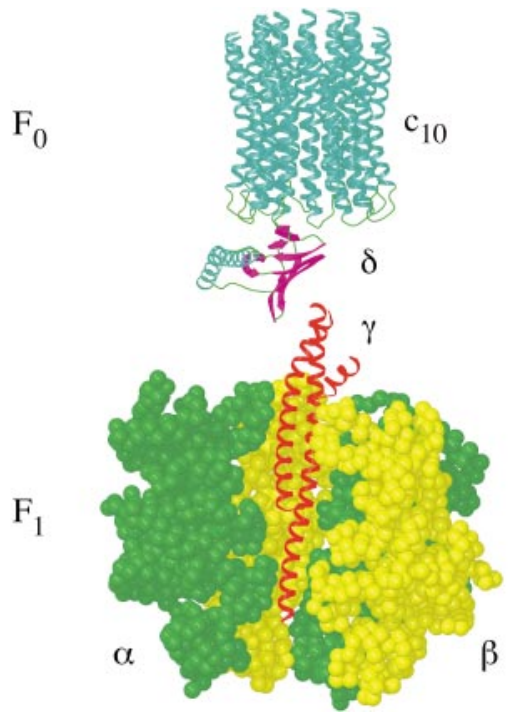

Figure 2 Structure of the $\mathrm{F}_{1} \mathrm{c}_{10}$-ATPase complex from $S$. cerevisiae (PDB accession code 1QO1). One $\alpha$ and one $\beta$ subunit have been removed to show the orientation of the $\gamma$ subunit. 


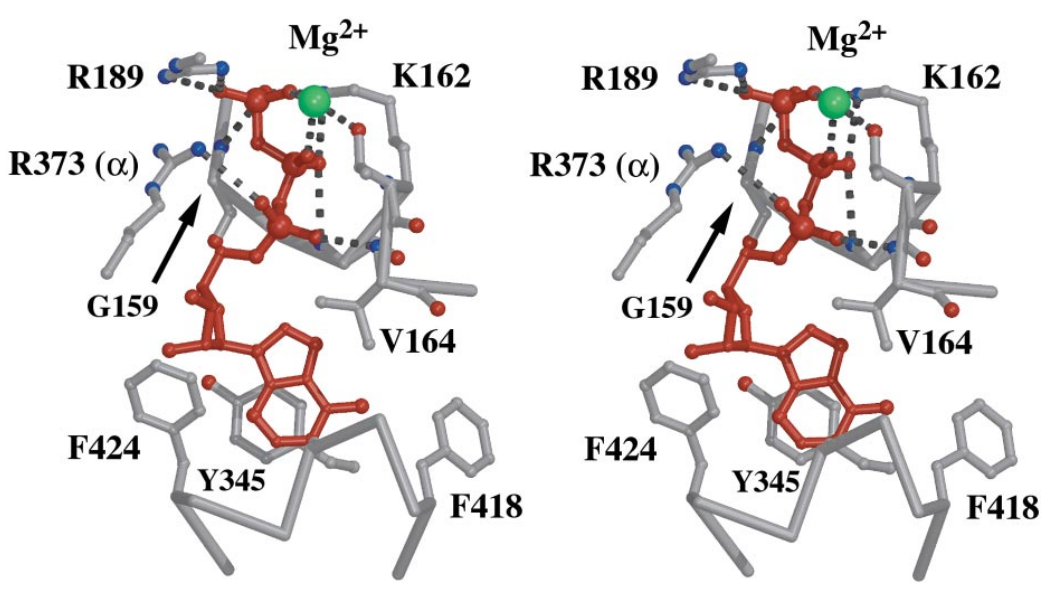

Figure 4 Stereo view of the ATP-binding site in the $\beta$ subunit of $\mathrm{F}_{1}$-ATPase (PDB accession code $1 \mathrm{BMF}$ ) containing the ATP analog AMP-PNP (shown in red). 


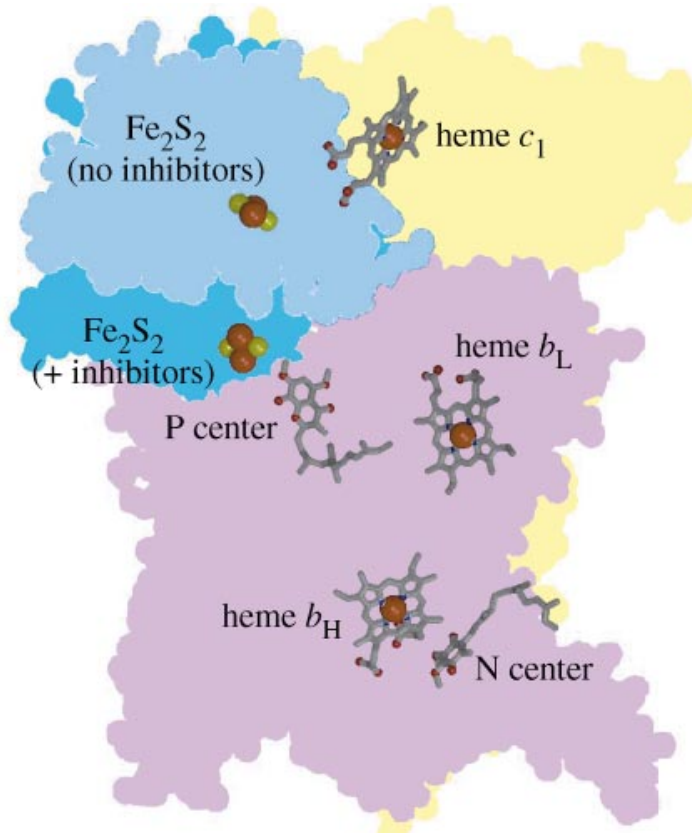

Figure 5 Crystal structure of cytochrome $b$ (purple), cytochrome $c_{1}$ (yellow), and the extramembranous domain of the iron-sulfur protein (dark blue) from one monomeric unit of cytochrome $b c_{1}$. Stigmatellin and antimycin are bound at the $\mathrm{P}$ and $\mathrm{N}$ centers of the protein, respectively. Superimposed on the structure is the position of the iron-sulfur protein in the absence of inhibitors (light blue), showing the range of the domain movement of the iron-sulfur protein. PDB accession codes 1BCC, 3BCC. 


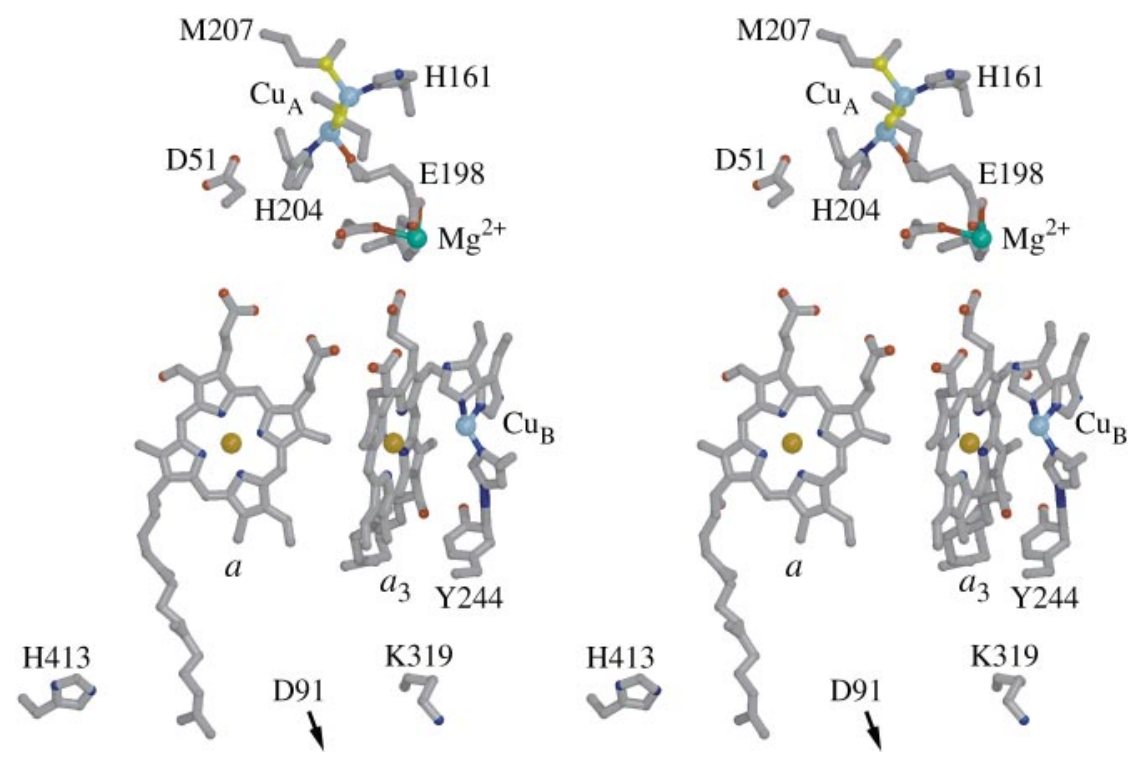

Figure 7 Stereo view of the prosthetic groups and selected amino acid residues in cytochrome $c$ oxidase. The ligands on the heme groups are removed for clarity. PDB accession code 1 OCC. 


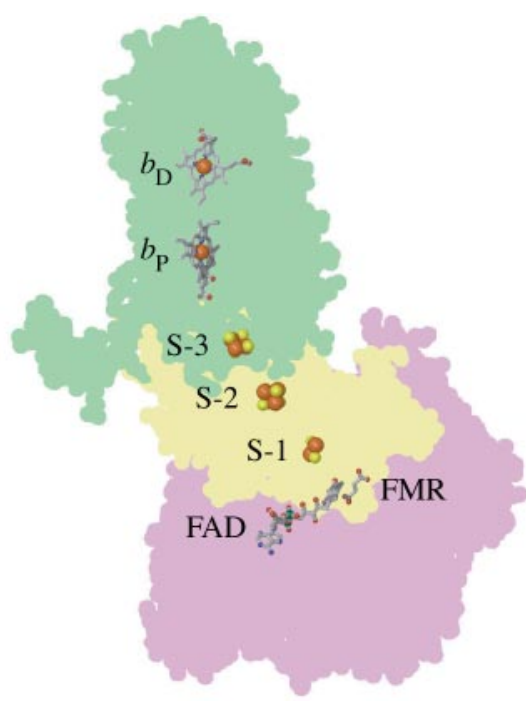

Figure 11 Structures of QFR enzymes from E. coli (left) and W. succinogenes (right). The membrane anchor (top), iron-sulfur protein (middle), and flavoprotein (bottom) are shown in green, yellow, and purple, respectively. OAA: oxaloacetate; FMR: fumarate. PDB accession codes 1FUM, 1QLB. 


\section{CONTENTS}

HYDROGEN BONDING, BASE STACKING, AND STERIC EFFECTS IN DNA REPLICATION, Eric T. Kool

STRUCTURES AND PROTON-PUMPING STRATEGIES OF MITOCHONDRIAL RESPIRATORY ENZYMES, Brian E. Schultz, Sunney I. Chan

MASS SPECTROMETRY AS A TOOL FOR PROTEIN CRYSTALLOGRAPHY, Steven L. Cohen, Brian T. Chait A STRUCTURAL VIEW OF Cre-loxP SITE-SPECIFIC RECOMBINATION, Gregory D. Van Duyne

PROBING THE RELATION BETWEEN FORCE--LIFETIME--AND CHEMISTRY IN SINGLE MOLECULAR BONDS, Evan Evans

NMR PROBES OF MOLECULAR DYNAMICS: Overview and Comparison with Other Techniques, Arthur G. Palmer III

STRUCTURE OF PROTEINS INVOLVED IN SYNAPTIC VESICLE FUSION IN NEURONS, Axel T. Brunger

AB INITIO PROTEIN STRUCTURE PREDICTION: Progress and Prospects, Richard Bonneau, David Baker

STRUCTURAL RELATIONSHIPS AMONG REGULATED AND UNREGULATED PHOSPHORYLASES, Jenny L. Buchbinder, Virginia L. Rath, Robert J. Fletterick

BIOMOLECULAR SIMULATIONS: Recent Developments in Force Fields, Simulations of Enzyme Catalysis, Protein-Ligand, Protein-Protein, and Protein-Nucleic Acid Noncovalent Interactions, Wei Wang, Oreola Donini, Carolina M. Reyes, Peter A. Kollman

CHAPERONIN-MEDIATED PROTEIN FOLDING, D. Thirumalai, George H. Lorimer

INTERPRETING THE EFFECTS OF SMALL UNCHARGED SOLUTES ON PROTEIN-FOLDING EQUILIBRIA, Paula R. DavisSearles, Aleister J. Saunders, Dorothy A. Erie, Donald J. Winzor, Gary J. Pielak

PHOTOSYSTEM II: The Solid Structural Era, Kyong-Hi Rhee

BINDING OF LIGANDS AND ACTIVATION OF TRANSCRIPTION BY NUCLEAR RECEPTORS, Anke C. U. Steinmetz, Jean-Paul Renaud, Dino Moras

PROTEIN FOLDING THEORY: From Lattice to All-Atom Models, Leonid Mirny, Eugene Shakhnovich

STRUCTURAL INSIGHTS INTO MICROTUBULE FUNCTION, Eva Nogales

PROPERTIES AND BIOLOGICAL ACTIVITIES OF THIOREDOXINS, Garth Powis, William R Montfort 